\title{
Nanostructured Copper Oxide on Silica-Zirconia Mixed Oxides by Chemical Implantation
}

\author{
Daniela Belli Dell'Amico, ${ }^{[\mathrm{a}]}$ Helmut Bertagnolli, ${ }^{[\mathrm{b}]}$ Fausto Calderazzo, ${ }^{[\mathrm{a}]}$ \\ Massimiliano D'Arienzo, ${ }^{[c]}$ Silvia Gross, ${ }^{[[d]}$ Luca Labella, ${ }^{[\mathrm{a}]}$ Marzio Rancan, ${ }^{[\mathrm{d}]}$ \\ Roberto Scotti, ${ }^{[c]}$ Bernd M. Smarsly, ${ }^{[e]}$ Ralf Supplit, ${ }^{[f]}$ Eugenio Tondello, ${ }^{[d]}$ and \\ Eric Wendel ${ }^{[b]}$
}

\begin{abstract}
N, N$-Dialkylcarbamato complexes of copper(II), $\left[\mathrm{Cu}\left(\mathrm{O}_{2} \mathrm{CNR}_{2}\right)_{2}\right]$ $\left(\mathrm{R}=\mathrm{All}=\right.$ allyl, $\left.\mathrm{C}_{3} \mathrm{H}_{5} ; i \mathrm{Pr}, \mathrm{CH}\left(\mathrm{CH}_{3}\right)_{2}\right)$ were prepared with the aim of functionalizing silica and nanostructured silica-zirconia matrices. The mixed matrices for the grafting reactions were prepared by copolymerizing MAPTMS (methacryloxypropyltrimethoxysilane), the precursor for the silica matrix, with the zirconium tetranuclear derivative $\left[\mathrm{Zr}_{4} \mathrm{O}_{2}(\mathrm{OMc})_{12}\right] \quad(\mathrm{OMc}=$ methacrylate $)$, the precursor for the zirconia nanoparticles. Suspension of the silica and silica-zirconia matrices in a solution of
\end{abstract}

the copper dialkylcarbamate led to the functionalization of the respective substrates. The composition, microstructure, morphology, and physicochemical nature of the copper species grafted on the matrices were investigated by FTIR, X-ray photoelectron spectroscopy (XPS), EPR, X-ray absorption spectroscopy (XAS), XRD, TEM, and dinitrogen adsorption. The effect of select-

Keywords: copper oxide $\cdot$ grafting • mixed oxides - nanostructures • surface chemistry ed experimental parameters (the nature of the copper precursor and of the matrix, grafting time, thermal treatment) on the grafting reaction was investigated. The $\mathrm{Cu} / \mathrm{Si}$ ratio is increased by increasing the grafting time and the $\mathrm{ZrO}_{2}-\mathrm{SiO}_{2}$ matrix is more reactive to attack by the carbamato complexes than either prepared or commercial $\mathrm{SiO}_{2}$. After functionalization of the matrix, thermal treatment yielded nanostructured copper(II) oxide clusters, average diameter $12-15 \mathrm{~nm}$, uniformly supported on the silica and on the silica-zirconia matrices.

\section{Introduction}

Surface nanostructuring and functionalization of materials are currently intensively studied areas in materials science and inorganic chemistry. ${ }^{[1-3]}$ The catalytic activities of nanostructured metal oxides on a support can differ from those of the corresponding bulk materials, and their dispersion on [a] Prof. D. B. Dell'Amico, Prof. F. Calderazzo, Prof. L. Labella Dipartimento di Chimica e Chimica Industriale Universitá di Pisa

Pisa, via Risorgimento 35, 56126 Pisa (Italy)

[b] Prof. H. Bertagnolli, Dr. E. Wendel Institut für Physikalische Chemie Universität Stuttgart Pfaffenwaldring 55, 70569 Stuttgart (Germany)

[c] Dr. M. D’Arienzo, Prof. R. Scotti Dipartimento di Scienze dei Materiali Università di Milano-Bicocca via Cozzi, 53, 20125 Milano (Italy)

[d] Dr. S. Gross, Dr. M. Rancan, Prof. E. Tondello CNR-ISTM, Dipartimento di Scienze Chimiche Universitá degli Studi di Padova and INSTM UdR Padova, via Marzolo, 1, 35131 Padova (Italy)

E-mail: silvia.gross@unipd.it [e] Prof. B. M. Smarsly Physikalisch-Chemisches Institut Justus Liebig Universität Giessen Heinrich-Buff-Ring 58, 35392 Giessen (Germany)

[f] Dr. R. Supplit Institut für Materialchemie Technische Universität Wien 1040 Vienna (Austria) Fax: (+39) 049-827-5161

Supporting Information (TGA results, SEM images, graphical comparisons of data) for this article is available on the WWW under http:// dx.doi.org/10.1002/chem.200801704. 
the substrate plays a major role in affecting the performance of the catalyst. ${ }^{[1,4-5]}$

The selectivity of a heterogeneous catalyst may be controlled through the size, the size distribution, and the dispersion of the nanoparticles on the support. In this framework, one of the general strategies for functionalizing other metal oxide or silica surfaces relies on the anchoring of transition metal polynuclear derivatives or complexes via the surface hydroxyl groups present on the metal oxide surface.

Metal-containing fragments have been dispersed on oxide supports by various methods, such as: a) chemical grafting using a metal alkoxide precursor; ${ }^{[6]}$ b) reaction of a suitable organometallic precursor with the acidic sites of the support ${ }^{[7]}$ c) reaction of inorganic precursors with the Brønsted acidic sites of silica or other oxides $;^{[8,9]}$ d) nucleophilic attack of surface hydroxyl groups on metal carbonyl clusters $;^{[10]}$ e) thermolysis of an organometallic or coordination compound. ${ }^{[11]}$ As far as c) is concerned, some of us ${ }^{[12]}$ have introduced a grafting method based on the use of $N, N$-dialkylcarbamato complexes, taking advantage of the reactivity of the metal-containing precursor toward the silanol sites of silica. This method has been called "chemical implantation" since it presents a reliable and effective route to the grafting of desired compounds or nanoparticles on a surface using well-defined chemical species as precursors. In the present case, these $N, N$-dialkylcarbamato precursors offer many advantages: a) they already contain an $\mathrm{M}-\mathrm{O}$ bond which is susceptible to attack by proton-active molecules; ${ }^{[12 \mathrm{~h}]}$ b) they are readily accessible for virtually all metals, ${ }^{[12 i]}$ c) the driving force of the implantation reaction, normally carried out at room temperature, is the release of $\mathrm{CO}_{2}$, thus leading to complete conversion. By this method, nanoparticles of $\mathrm{Pd}$, $\mathrm{Au}$, or Pt with diameter $<10 \mathrm{~nm}$ were "chemically implanted" on silica [Eq. (1)]. ${ }^{[12]}$

$$
\begin{aligned}
& {\left[\mathrm{M}\left(\mathrm{O}_{2} \mathrm{CNR}_{2}\right)_{n}\right]+m(\# \mathrm{Si}-\mathrm{OH}) \rightleftharpoons} \\
& \quad\left[(\# \mathrm{SiO})_{m} \mathrm{M}\left(\mathrm{O}_{2} \mathrm{CNR}_{2}\right)_{n-m}\right]+m \mathrm{CO}_{2}+m \mathrm{NHR}_{2}
\end{aligned}
$$

In the present study, we used the $N, N$-dialkylcarbamato complexes of copper(II), $\left[\mathrm{Cu}\left(\mathrm{O}_{2} \mathrm{CNR}_{2}\right)_{2}\right]$, to functionalize silica and silica-zirconia matrices with copper. In particular, $\left[\mathrm{Cu}\left(\mathrm{O}_{2} \mathrm{CNiPr}\right)_{2}\right]^{[13,14]}$ and $\left[\mathrm{Cu}\left(\mathrm{O}_{2} \mathrm{CNAll}\right)_{2}\right]$ were prepared and used as copper oxide precursors. Copper-based catalysts were chosen for their interesting catalytic properties ${ }^{[15-17]}$ in several processes such as the abatement of pollutants, the decomposition of $\mathrm{NO}_{x}$ and $\mathrm{N}_{2} \mathrm{O}$, and the selective reduction of $\mathrm{NO}_{x}$ to $\mathrm{N}_{2},{ }^{[18-21]}$ as well as for their low cost compared to catalysts based on noble metals. ${ }^{[18]}$

For these applications, dispersion is one of the key factors affecting the catalytic activity. Several synthetic routes, such as wet impregnation, chemisorption/hydrolysis, ${ }^{[22]}$ ion exchange, and grafting or evaporation on silica, ${ }^{[23]}$ have been used to disperse copper species on single oxide or mixedoxide matrices. Gervasini et al. ${ }^{[24]}$ have reported $\mathrm{CuO}$-based catalysts supported on niobium phosphonate ${ }^{[15]}$ silica, silicatitania, ${ }^{[25]}$ and silica-alumina matrices, whereas the mecha- nism of methanol decomposition was studied on $\mathrm{Cu} / \mathrm{SiO}_{2}$ or $\mathrm{Cu} / \mathrm{ZrO}_{2} / \mathrm{SiO}_{2}$. ${ }^{[18,26]}$

Here we have selected the supporting $\mathrm{SiO}_{2}-\mathrm{ZrO}_{2}$ matrices according to the best combination of textural and microstructural properties to make them useful as catalysts ${ }^{[33]}$ or catalyst supports: $:^{[34,35]}$ good mechanical strength, acceptable surface area and pore volume, good chemical resistance, good thermal and mechanical stabilities, low thermal expansion, ${ }^{[27-31]}$ and high surface acidity. ${ }^{[32]}$

Our synthetic route is based on four steps (Scheme 1):

1) preparation of the silica or silica-zirconia matrices;

2) synthesis of the copper(II) precursors;

3) grafting reaction;

4) calcination in air.

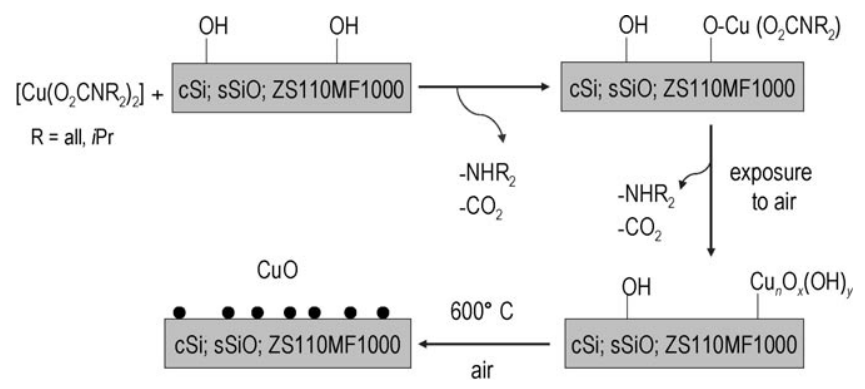

Scheme 1. The grafting procedure.

This route to "chemical implantation" on the silica-based matrices leads to a homogeneous dispersion of the metal oxide on the surface and avoids uncontrolled agglomeration and growth of the supported oxide.

The grafting reactions were carried out on commercial silica, as well as on silica and mixed silica-zirconia oxides

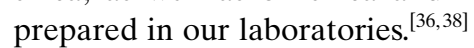

The extent of the functionalization, as described below, was evaluated as a function of various experimental parameters, namely: a) the type of matrix (commercially available or synthesized); b) the type of $N, N$-dialkylcarbamato complex; c) the duration of the matrix-precursor interaction ( 1 , $3,5,10$, or 15 days); d) the type of thermal treatment (conventional or microwave).

\section{Results and Discussion}

The compositional and microstructural features of the matrices are described extensively elsewhere. ${ }^{[36-38]}$

Microstructure analysis: To evaluate the effect of the surface and morphology of the matrices on the grafting efficiency, the specific surface area of the samples was determined before the grafting experiments by dinitrogen adsorption analysis: samples ZS110 MF1000 and sSi show type IIa isotherms (Figure 1$)^{[49]}$ typical of nonporous or macroporous 

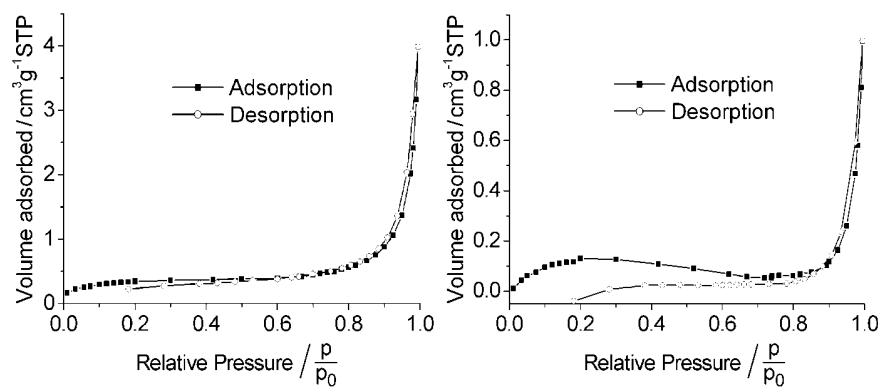

Figure 1. Dinitrogen adsorption of ZS110 MF1000 (left) and sSi (right).

materials with a low amount of mesoporosity. Surface areas were 1.2 and $0.5 \mathrm{~m}^{2} \mathrm{~g}^{-1}$, respectively.

The main features of the three matrices are summarized in Table 1.

Table 1. Main microstructural features of the matrices.

\begin{tabular}{lclc}
\hline Sample & $\begin{array}{l}\text { Specific surface } \\
\text { area }\left[\mathrm{m}^{2} \mathrm{~g}^{-1}\right]\end{array}$ & $\begin{array}{l}\text { Specific pore } \\
\text { volume }\left[\mathrm{cm}^{3} \mathrm{~g}^{-1}\right]\end{array}$ & $\begin{array}{l}\text { Pore size } \\
{[\mathrm{nm}]}\end{array}$ \\
\hline $\mathrm{ZrO}_{2}-\mathrm{SiO}_{2}$ & 1.2 & $6.17 \times 10^{-3}$ & 19.4 \\
$\mathbf{s S i}$ & 0.5 & $1.44 \times 10^{-3}$ & 11.0 \\
$\mathbf{c S i}$ & 468 & $7.49 \times 10^{-1}$ & 6.4 \\
\hline
\end{tabular}

However, the experimental uncertainties are increased for samples ZS110 MF1000 and sSi because of their low surface areas, which might also cause the unusual hysteresis between the desorption and adsorption isotherms (Figure 1).

The nitrogen sorption plot of $\mathbf{c S i}$ in Figure 2 shows instead a type $\mathrm{IVb}$ isotherm with an $\mathrm{H} 2$ hysteresis. ${ }^{[49]}$ This is typical of dried gels of inorganic oxides, characterized by a network of interconnected pores of different forms and sizes. The BET analysis shows a surface area of about $470 \mathrm{~m}^{2} \mathrm{~g}^{-1}$.

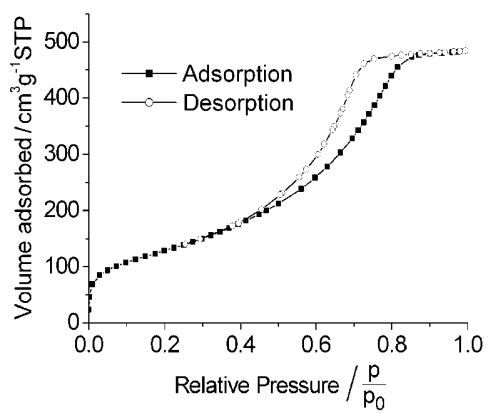

Figure 2. Dinitrogen adsorption of $\mathbf{c S i}$.

Thermal behavior: Firstly, TGA was used to investigate the stability of the grafted samples under annealing. The sample ZS110 MF1000 Cu1-10 in air (Figure S1 in the Supporting Information) is characterized by a small weight loss of about
$1.6 \%$ up to $800^{\circ} \mathrm{C}$ : the first weight loss $(0.4 \%)$ up to 200 $300^{\circ} \mathrm{C}$ can be ascribed to evaporation of residual solvent, whereas above $400{ }^{\circ} \mathrm{C}$ the decrease in weight is attributed to the condensation of $\mathrm{OH}$ groups with release of water. No further relevant weight loss was detected; this could be ascribed to release of grafted copper oxide induced by the thermal treatment. Since similar low weight losses were observed also for the nonimpregnated matrices, the grafted materials can be considered thermally stable.

Grafting experiments: As mentioned in the Introduction, three experimental parameters varied in the grafting experiments: a) the type of matrix; b) the nature of the $\mathrm{N}, \mathrm{N}$-dialkylcarbamato complex; and c) the grafting time. In particular, we used three different types of matrices (commercial silica, synthetic silica, silica-zirconia), two different coppercontaining precursors, and different grafting times, that is, the duration of interaction between the matrix and the solution of the copper precursor (see the Experimental Section and Table 3, below). Additionally, selected samples characterized by a higher amount of zirconium $(\mathbf{Z S 1 2 5})$ were treated at $600^{\circ} \mathrm{C}$ by both conventional and microwave heating to investigate the influence on the amount of grafted copper oxide of a) the zirconium content; b) the kind of thermal treatment; and c) the temperature of annealing. In the grafting experiments a high copper precursor concentration $(0.5 \mathrm{M})$ was used to avoid a significant consumption of the grafting agent and also to ensure a large excess of copper over long impregnation times. Accordingly, no decoloration of the precursor solution was observed, whereas the impregnated matrices acquired the typical blue-green color of the precursor solution.

Microstructure, morphology, and composition of the $\mathrm{Cu}_{\mathrm{n}} \mathrm{O}_{\mathrm{x}}(\mathrm{OH})_{\mathrm{y}}-\mathrm{SiO}_{2}-\mathrm{ZrO}_{2}$ systems: The composition of the functionalized systems was investigated by IR spectroscopy and by XPS. The latter method is particularly suitable for the investigation of these systems since it can analyze the chemical environment and, being a highly surface-sensitive method, it allows a reliable quantification of copper species grafted on the surface.

In Figure 3, the IR spectrum of the untreated commercial silica is compared with the spectra of the same silica treated with the two carbamato complexes.

The IR spectra show no bands in the spectral range 1300$1600 \mathrm{~cm}^{-1}$, thus excluding the presence ${ }^{[12]}$ of $N, N$-dialkylcarbamato groups.

The strong bands at 1091 and $800 \mathrm{~cm}^{-1}$ are attributed to the asymmetric and symmetric $\mathrm{Si}-\mathrm{O}-\mathrm{Si}$ stretching of silica, respectively. ${ }^{[36-38]}$ The weak shoulder at $960 \mathrm{~cm}^{-1}$, attributed to the $\mathrm{Si}-\mathrm{OH}$ stretching, is of lower intensity after the grafting reaction with both $N, N$-dialkylcarbamato complexes, as expected, due to the reaction with the silanol groups of the silica. The same features were observed also in all the IR data of the other functionalized samples (data not shown), thus proving the efficiency of the adopted method. The systems were characterized by XPS data, which, in combination 


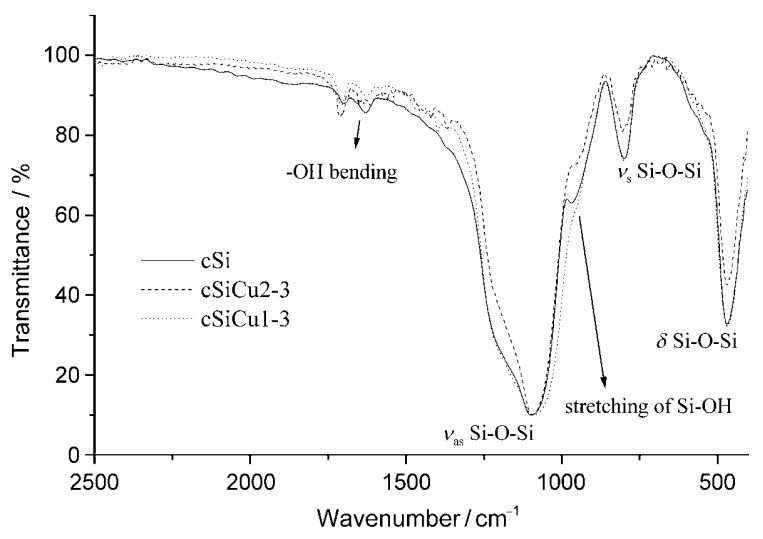

Figure 3. IR spectra of samples cSi Cu1-3, cSi, and cSi Cu2-3.

with the XAS studies, shed light on the nature of the $\mathrm{Cu}-$ matrix interaction. The XPS survey of sample ZS110MF1000 Cu1-5 and details of the $\mathrm{Cu} 2 \mathrm{p}$ region are shown in Figure 4.

For copper, the $\mathrm{BE}$ values of the $\mathrm{Cu} 2 \mathrm{p}_{3 / 2}$ peak, ranging from 932.2 to $933.5 \mathrm{eV}$, cannot be used to define unambiguously the oxidation state of copper and the chemical environment. It is well known that $\mathrm{Cu}^{\mathrm{II}}$ and $\mathrm{Cu}^{\mathrm{I}}$ are difficult to distinguish, their binding energies being quite similar $(\mathrm{CuO}$ $\left.933.6 \mathrm{eV} ; \mathrm{Cu}_{2} \mathrm{O} 932.5 \mathrm{eV}\right) .{ }^{[40,41]}$ In this case, other typical fea-
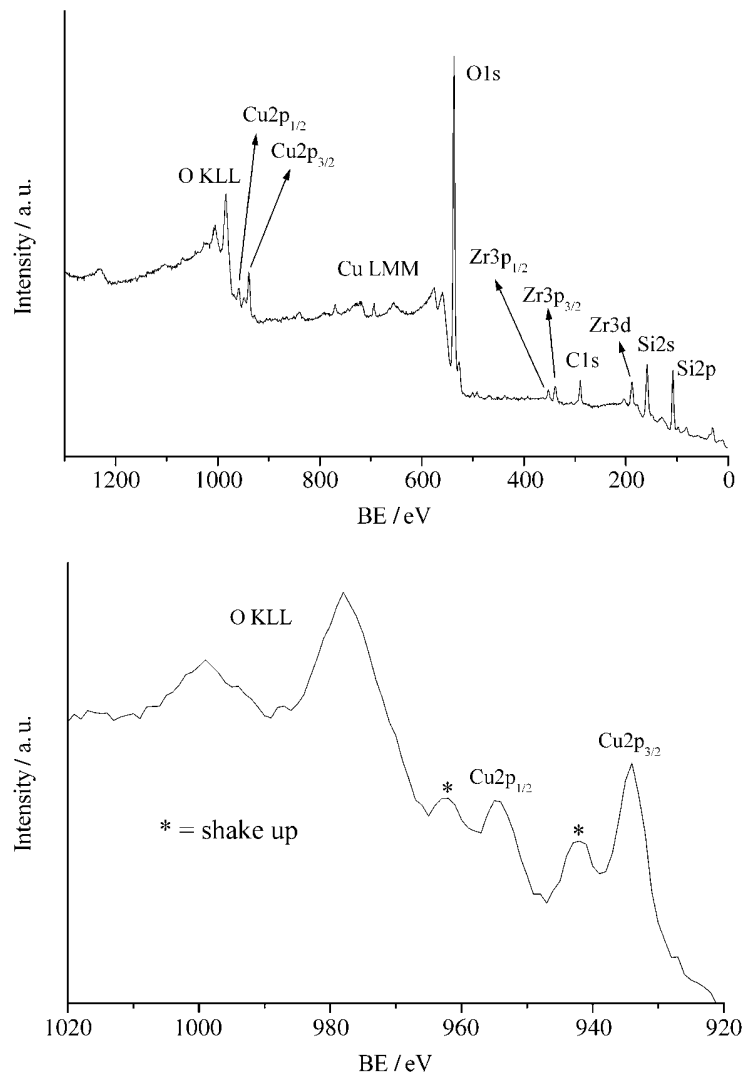

Figure 4. XPS survey of the sample ZS110 MF1000 Cu1-5 (above) and the $\mathrm{Cu} 2 \mathrm{p}$ XPS region of sample ZS110MF1000Cu1-5 (below; the plotted spectrum is not corrected for charging effects). tures of the XPS spectrum, mainly the shape of the copper $\mathrm{Cu} 2 \mathrm{p}$ region, can lead to a safer assignment, due to the presence, in $\mathrm{Cu}^{\mathrm{II}}$ species, of the $\mathrm{Cu} 2 \mathrm{p}_{1 / 2}$ and $\mathrm{Cu} 2 \mathrm{p}_{3 / 2}$ peaks along with their shake-up satellites. ${ }^{[15,23,24]}$ In particular, in the reported spectrum of Figure 4 the peaks are at $933.9 \mathrm{eV}$ and $953.7 \mathrm{eV}$, whereas the two satellites are at 939.4 and $959.2 \mathrm{eV}$, respectively. These findings indicated the presence of $\mathrm{Cu}^{\mathrm{II}}$, which was also confirmed by EPR and extended Xray absorption fine structure (EXAFS) data discussed below.

The $\mathrm{BE}$ of the $\mathrm{Zr} 3 \mathrm{~d}$ and $\mathrm{Si} 2 \mathrm{p}$ regions (selected regions not shown) are observed at 182.8-183.4 and 102.8-103.6 eV, respectively, which are typical of the corresponding dioxides, as reported elsewhere. ${ }^{[37,38]}$ Furthermore, the experimental $\mathrm{Si} / \mathrm{Zr}$ molar ratio is 10 , in agreement with the nominal composition of the solution used for the synthesis of the matrix. The $\mathrm{BE}$ in the $532.2-532.6 \mathrm{eV}$ region is typical of $\mathrm{O} 1 \mathrm{~s}$ in a silica environment. ${ }^{[40,41,42]}$

In sample sSi Cu1, the $\mathrm{BE}$ values of the $\mathrm{Cu} 2 \mathrm{p}$ region are slightly higher than in the other samples $(934.7 \mathrm{eV})$, and this finding can be ascribed, according to observations made by other authors also, ${ }^{[23,24,43,44]}$ to an interaction with the support oxide, which in turn would demonstrate the fine dispersion of the copper species. If $\mathrm{CuO}$ were present in an agglomerate state, the $\mathrm{BE}$ typical of bulk $\mathrm{CuO}$ would be observed instead. In this case, the presence of well-dispersed $\mathrm{Cu}^{\mathrm{II}}$ species interacting with the $\mathrm{OH}$ groups of the silica support $(935.3 \mathrm{eV})$ could be inferred. ${ }^{[24,43]}$

XRD and TEM measurements shed some light on the microstructure of the materials.

After the grafting experiments and the thermal annealing at $600{ }^{\circ} \mathrm{C}$, the XRD pattern of sample ZS110 MF1000 Cu1-3 (Figure 5) contains the typical reflections of tetragonal zirconia ${ }^{[38]}$ as well as further reflections peaking at $35.5^{\circ}$ and at $38.8^{\circ}$ which overlap with them. Less intense features are present at $2 \theta=48.8^{\circ}, 53.3^{\circ}, 58.2^{\circ}, 61.6^{\circ}, 66.1^{\circ}$, and $67.0^{\circ}$. This pattern corresponds to the monoclinic copper oxide tenorite ${ }^{[45]}$ the two most intense reflections corresponding to the

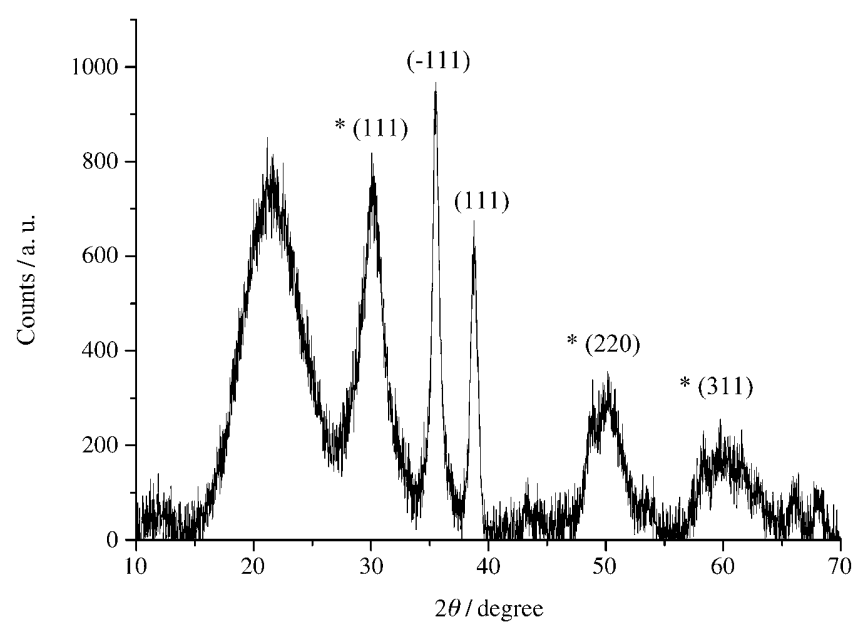

Figure 5. XRD pattern of sample ZS110MF1000Cu1-3 after thermal treatment at $600^{\circ} \mathrm{C}$. *: Reflections ascribed to the matrix. 
(111) $\left(35.5^{\circ}\right)$ and (111) $\left(38.8^{\circ}\right)$ crystallographic planes. The Scherrer formula ${ }^{[46,47]}$ applied to the most intense reflection (111) determined an average crystallite size of $13 \mathrm{~nm}$.

The presence of well-dispersed spherical and oblate copper oxide nanoparticles with an average diameter of about $12-15 \mathrm{~nm}$ was also confirmed by TEM, in agreement with the XRD results. As can be seen in Figure 6 for sample ZS110 MF1000 Cu1-3, the nanoparticles are grafted homogeneously on the surface of the silica-zirconia matrix and well separated, thus confirming that the chosen synthetic route yields a homogeneous dispersion.
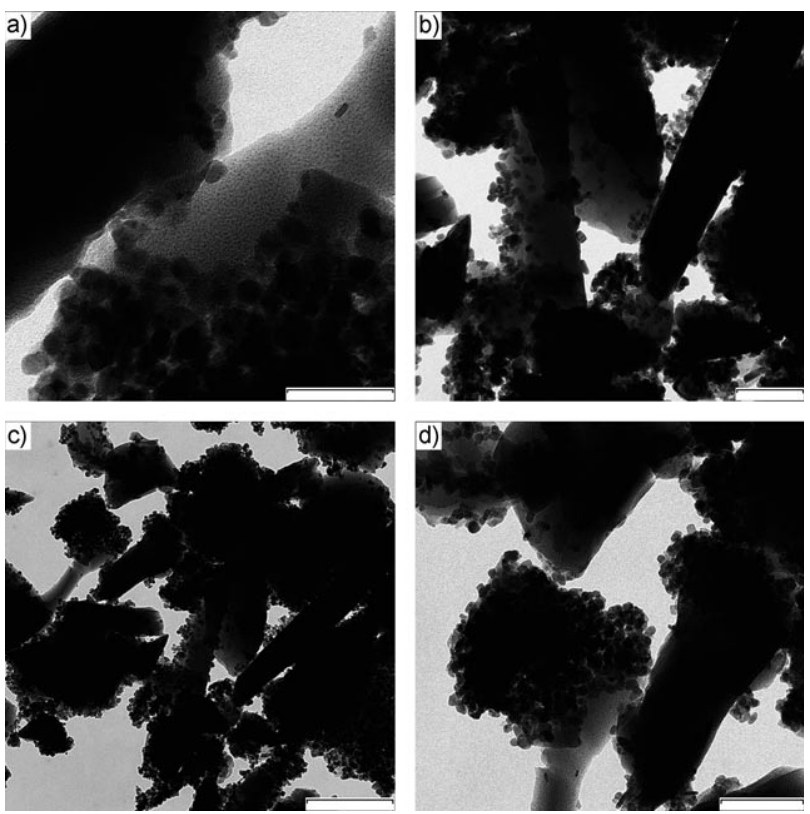

Figure 6. TEM micrographs of sample ZS110 MF1000 Cu1-3 after thermal treatment at $600^{\circ} \mathrm{C}$. Scale bar a) $100 \mathrm{~nm}$; b) $200 \mathrm{~nm}$; c) $500 \mathrm{~nm}$; d) $200 \mathrm{~nm}$

The morphology of the "chemically implanted" materials was investigated by SEM. Two representative images of sample ZS110 MF1000Cu1-3 at different magnifications (found in Figure S4 of the Supporting Information) provide evidence of the presence of compact grains of different volumes and morphologies. Energy-dispersive X-ray (EDX) analysis confirmed the $\mathrm{Zr} / \mathrm{Si}$ atomic ratio obtained by XPS $(\mathrm{Zr} / \mathrm{Si}=1: 10)$ and also a $\mathrm{Cu} / \mathrm{Si}$ ratio of about $3: 1$, in perfect agreement with XPS data.

Evolution of the $\mathrm{Cu}$ environment upon annealing: To study the change in $\mathrm{Cu}^{\mathrm{II}}$ coordination due to the annealing treatment of grafted $\left[\mathrm{Cu}\left(\mathrm{O}_{2} \mathrm{CNi} \mathrm{Pr}_{2}\right)_{2}\right]$, EPR spectra were recorded at $123 \mathrm{~K}$ after the samples had been heated in air to $800^{\circ} \mathrm{C}$ in steps of $100^{\circ} \mathrm{C}$.

The EPR spectra of ZS110 MF1000 Cu1-3 showed the resonance lines of isolated, magnetically diluted, $\mathrm{Cu}^{\mathrm{II}}$ centers with $\mathrm{g}_{\|}=2.331, \mathrm{~g}_{\perp}=2.071$, and $A_{\|}=151 \mathrm{G}$ (Figure $7 \mathrm{a}$ ), in

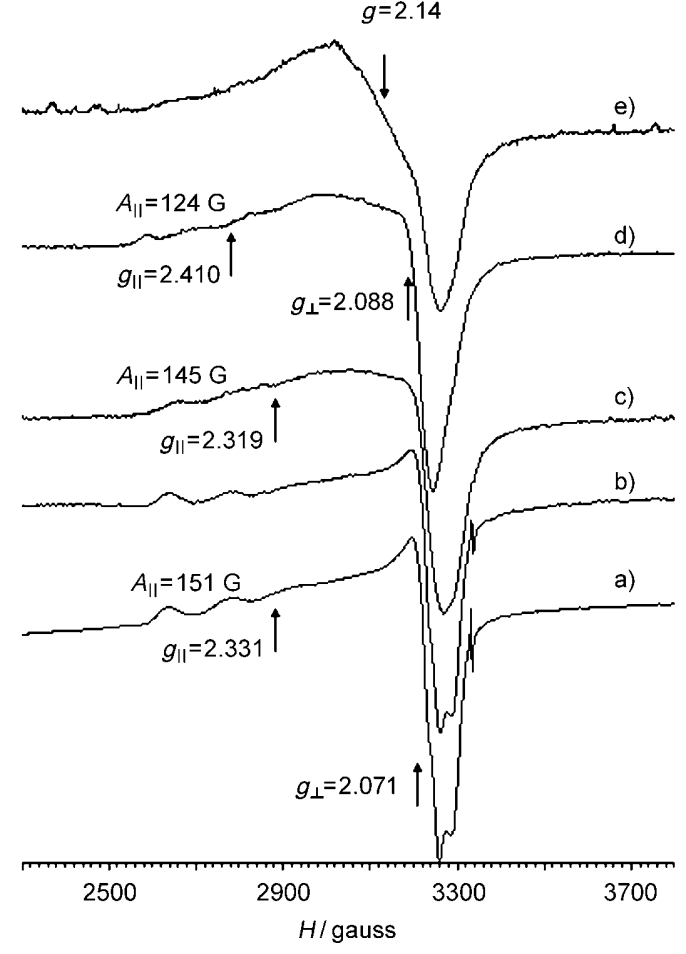

Figure 7. EPR spectra $(T=123 \mathrm{~K})$ of sample ZS110 MF1000 Cu1-3 a) as prepared, and after annealing in air at: b) $100^{\circ} \mathrm{C}$; c) $300^{\circ} \mathrm{C}$; d) $500^{\circ} \mathrm{C}$; e) $700^{\circ} \mathrm{C}$.

agreement with XPS evidence for the presence of copper in the $\mathrm{Cu}^{\mathrm{II}}$ oxidation state.

The magnetic tensor values $\left(\mathrm{g}_{\|} \gg \mathrm{g}_{\perp}>\mathrm{g}_{\mathrm{e}}\right.$, ground state: $\left.d_{x^{2}-y^{2}}\right)$ are typical of bivalent copper in axial symmetry, consistent with tetragonally elongated octahedral or squareplanar or square-pyramidal ions with four oxygen ligands in the equatorial positions. ${ }^{[48]}$ The coordination number of 4 found for $\mathrm{Cu}^{\mathrm{II}}$ ions from EXAFS experiments (see under Effect of the temperature and type of thermal treatment, below) confirms the tetragonal symmetry of the environment, as already found in similar systems. ${ }^{[49]}$ The calculated $\mathrm{Cu}^{\mathrm{II}}$ content of the samples, about $6.8 \mathrm{wt} \%$, is evidence for a relevant amount of grafted copper oxide, but it cannot be compared with the results of XPS, which is a surface-sensitive method whereas EPR probes the whole bulk. After the annealing at $100^{\circ} \mathrm{C}$ (Figure $7 \mathrm{~b}$ ) and $200^{\circ} \mathrm{C}$, the spectra were similar and did not change with respect to the as-prepared samples. After the annealing at $300{ }^{\circ} \mathrm{C}$ (Figure $7 \mathrm{c}$ ) and $400^{\circ} \mathrm{C}$, the EPR spectra were slightly broader and showed small differences in the magnetic parameters of $\mathrm{Cu}^{\mathrm{II}}$ isolated species $\left(g_{\|}=2.319, g_{\perp}=2.078, A_{\perp}=145 \mathrm{G}\right)$, due to small changes in copper coordination. These $\mathrm{Cu}^{\mathrm{II}}$ centers accounted for about $70 \%$ of the initial concentration. After annealing at $500{ }^{\circ} \mathrm{C}$, (Figure $7 \mathrm{~d}$ ), the content of the $\mathrm{Cu}^{\mathrm{II}}$ centers decreased further, to about $63 \%$ of the as-prepared sample. The spectra of the isolated $\mathrm{Cu}^{\mathrm{II}}$ centers were poorly resolved due to the superposition of a broad resonance at $\mathrm{g} \approx 2.1-2.2$ (vide infra). Their new magnetic parameters $\left(g_{\|}=2.410\right.$, 
$g_{\perp}=2.088, A_{\|}=124 \mathrm{G}$ ) are still consistent with those of bivalent copper with oxygen atoms in tetragonal symmetry. Their variation is a consequence of the different coordination environment of the grafted $\mathrm{Cu}^{\mathrm{II}}$ centers after $[\mathrm{Cu}-$ $\left.\left(\mathrm{O}_{2} \mathrm{CNiPr}\right)_{2}\right)_{2}$ decomposition, with a higher tetragonal distortion $^{[49]}$ and/or a lower charge on copper. ${ }^{[48]}$ After the annealing at $700{ }^{\circ} \mathrm{C}$ (Figure $7 \mathrm{e}$ ) and $800^{\circ} \mathrm{C}$ (spectrum not shown), the spectra showed the presence of a broad band at $g=2.14$, attributed to magnetically coupled $\mathrm{Cu}^{\text {II }}$ centers, ${ }^{[50]}$ superimposed on the residual resonance lines of isolated $\mathrm{Cu}^{\mathrm{II}}$ centers. The paramagnetic copper totaled about $40 \%$ of the original quantity: this suggests a partial segregation of $\mathrm{CuO}$ with part of the copper still dispersed in the matrix. No EPR signal below the Néel temperature is expected for a $\mathrm{CuO}$ antiferromagnetic phase. ${ }^{[51,52]}$

XPS analyses carried out on the grafted sample showed that the $\mathrm{Cu} / \mathrm{Si}$ atomic ratio changed from 1:2 before thermal annealing at $600{ }^{\circ} \mathrm{C}$ in air to $1: 3.5$ after the treatment; that is, an appropriate decrease in copper content was observed, which could be due to the segregation of $\mathrm{CuO}$ nanoparticles of average diameter about $12-15 \mathrm{~nm}$, as detected by TEM analyses (vide supra). Since the sampling depth of X-rays in XPS analysis is about $4-5 \mathrm{~nm}$, formation of larger nanoparticles would lead to underestimation of the amount of copper.

Effect of the experimental parameters on the grafting efficiency and copper oxide loading: The functionalized, as-prepared samples (that is, without post-treatment at $600^{\circ} \mathrm{C}$ ) were analyzed by XPS to evaluate the extent of the grafted copper complex from the $\mathrm{Cu} / \mathrm{Si}$ atomic ratio. Table 2 summarizes the $\mathrm{Cu} / \mathrm{Si}$ atomic ratios determined by XPS quantitative analysis, as a function of the respective experimental conditions.

Table 2. $\mathrm{Cu} / \mathrm{Si}$ atomic ratios in the different samples as a function of the grafting time.

\begin{tabular}{lllll}
\hline & \multicolumn{3}{c}{ Days } \\
Sample & 1 & 3 & 5 & 10 \\
\hline cSiCu1 & $1: 46$ & $1: 36$ & $1: 30$ & $1: 32$ \\
cSiCu2 & $1: 49$ & $1: 42$ & $1: 32$ & $1: 27$ \\
SSi Cu1 & - & $1: 4$ & $1: 3$ & $1: 2$ \\
SSi Cu2 & - & $1: 31$ & $1: 23$ & $1: 19$ \\
ZS110 MF1000 Cu1 & - & $1: 8$ & $1: 3$ & $1: 2$ \\
ZS110 MF1000 Cu2 & $1: 36$ & $1: 22$ & $1: 16$ & $1: 10$ \\
ZS125 MW600 Cu1 & - & $1: 5.5$ & - & - \\
ZS125 MF600 Cu1 & - & $1: 1.5$ & - & - \\
ZS125 MF1000 Cu1 & - & $1: 5.2$ & - & - \\
\hline
\end{tabular}

Effect of grafting time: The interaction time (also called "grafting time" below) between the precursor in solution and the matrix is an important parameter. In general, other conditions being unchanged, a higher grafting time leads to a higher copper loading. This can be observed in Figure S2a-c (Supporting Information) and Table 2, plots of the $\mathrm{Cu} / \mathrm{Si}$ atomic ratios for various systems as a function of the grafting time. As a general trend, increasing the time of in- teraction leads to an increased $\mathrm{Cu} / \mathrm{Si}$ molar ratio determined by XPS, although the slopes of the curves differ according to the different matrices. In particular, a "damping effect" was observed in commercial silica, as discussed below.

From these data it can be concluded that, at least in the intervals of time (1-10 days) investigated, the proportion of grafted copper varies. As the silica and silica-zirconia matrices especially are characterized by high amounts of surface hydroxyls and Brønsted acidity, ${ }^{[51]}$ a more extensive impregnation can be attributed to the role of the grafting time, enabling a higher number of carbamate precursors to undergo electrophilic attack by the $\mathrm{OH}$ groups.

Extensive studies by Belli et al. ${ }^{[12 g-o]}$ on the use of carbamates as precursors for grafting reactions have demonstrated that the grafting reaction of metal carbamates $(\mathrm{Ru}, \mathrm{Pd}$, $\mathrm{Pt}, \mathrm{Ag}, \mathrm{Au}$, and so on) to silica matrices is generally fast and quantitative. In the present case, the observed "grafting time effect" can be explained by considering that the increased amount of copper detected on the surface as a function of the increasing impregnation time could be ascribed not only to the grafting reaction, but also to the concurrent hydrolysis. The rate of this latter reaction depends not only on the chemical nature and on the steric hindrance of the $\mathrm{R}$ moieties, but also on the trace amounts of water present in the system. Furthermore, whenever the hydrolysis reactions involve the already grafted copper centers, the formation of $\mu$-oxo aggregates could also be invoked to explain the longer reaction time observed.

Effect of the chemical nature of the precursors: The nature of the $N, N$-dialkylcarbamato precursor was found to affect strongly the extent of grafting. In particular, as can be inferred from Table 2, other conditions being maintained, precursor $\mathbf{C u 1}$ was proven to be more reactive with the matrices than the $\mathbf{C u 2}$ complex and to be more effective in promoting the anchoring to the silica-zirconia support. This can be visualized better in Figure S2 a-c (Supporting Information), in which the reactivities of the two copper precursors $\mathbf{C u 1}$ and $\mathbf{C u} 2$ toward the three different substrates are compared graphically.

This effect can be rationalized by considering the high reactivity of the $\left[\mathrm{Cu}\left(\mathrm{O}_{2} \mathrm{CNi} \mathrm{Pr}_{2}\right)_{2}\right]$ precursor, which is known to hydrolyze faster to give an octanuclear species.

Effect of the chemical nature of the matrix and of the amount of zirconium: The most important parameter affecting the efficiency of the grafting reaction is the chemical nature of the matrix. The reactivity of the three different matrices (evaluated in terms of loaded copper) decreases in the order $\mathbf{Z S 1 1 0 ~ M F 1 0 0 0}>\mathbf{S S i} \gg \mathbf{C S i}$. This trend can be visualized better in Figure 8 , where the $\mathrm{Cu} / \mathrm{Si}$ atomic ratios corresponding to the anchoring of complex $\mathbf{C u 1}$ to the three different matrices are compared. The corresponding trends for the $\mathbf{C u} \mathbf{2}$ complex are reported in the Supporting Information, Figure S3. Although there was a lower grafting efficiency for the $\mathbf{C u} 2$ precursor, the trend is confirmed in both cases. 


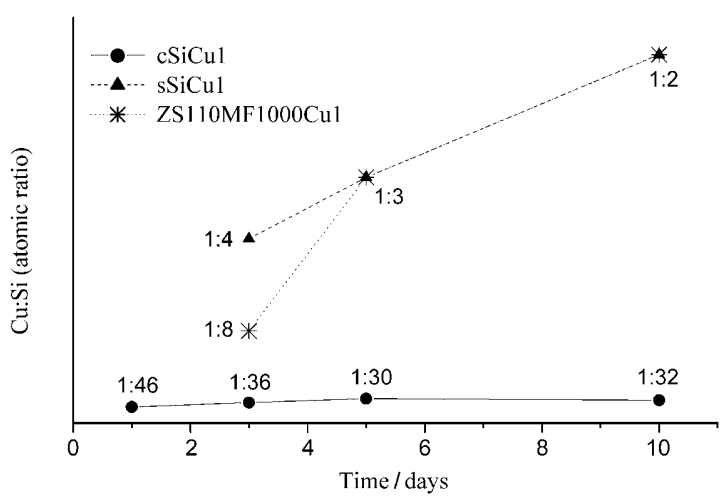

Figure $8 . \mathrm{Cu} / \mathrm{Si}$ atomic ratios as a function of the grafting time and of the nature of the different matrices for precursor $\mathbf{C u 1}$.

This finding can be explained on the basis of the different tendencies of the three matrices to attack the carbamato precursor electrophilically. The commercial pure silica matrix (cSi) displays a remarkably higher specific surface area than the synthesized one (sSi) (see Table 1). In this case, the difference in reactivity can reasonably be ascribed to the higher surface defectivity of the synthesized materials and to the high relative proportion of $\mathrm{OH}$ groups on the surface, evidenced by $\mathrm{IR}^{[38]}$ and diffuse reflectance IR Fourier transform (DRIFT) analyses reported elsewhere. ${ }^{[52,53]}$

As far as the silica-zirconia system is concerned, a recent investigation of the surface acidity of the mixed $\mathrm{ZrO}_{2}-\mathrm{SiO}_{2}$ systems using DRIFT ${ }^{[52]}$ has shown that they are characterized by a remarkable Brønsted surface acidity that is higher than in silica. ${ }^{[53]}$ This would explain the higher grafting efficiency of the mixed-oxide matrix than of pure silica. ${ }^{[38,53]}$

Also, Gervasini, Ravasio, and coworkers have reported that the acidity of silica and silicaalumina supports strongly affects both the anchoring and the catalytic activity of $\mathrm{CuO}$ based catalysts, and provided evidence that a poor dispersion of the $\mathrm{CuO}$ phase is to be ascribed to a lower concentration of acidic sites on the support. ${ }^{[15,24,25,54]}$ For the mixed oxides, the amount of zirconium also was proven to affect the amount of anchored copper. By comparing two samples characterized by different amounts of zirconium $(\mathrm{Zr} / \mathrm{Si}=1: 2.5$ and $1: 10)$, treated at the same temperature and impregnated with Cu1 for three days (see Table 2), the amount of copper oxide is slightly higher $(\mathrm{Cu} / \mathrm{Si}=$ 1:5.2 versus $1: 8)$ in the sample with the higher content of zirclarity. conium $(\mathrm{Zr} / \mathrm{Si}=1: 2.5) \cdot{ }^{[38,53]}$ DRIFT studies confirmed that the presence of zirconium oxide enhances the number and the acid strength of hydroxyl groups on mixed-oxide matrices. Moreover, the Cu1 precursor damps down the effect of the nature of the matrix relative to the $\mathbf{C u 2}$ complex (Figure 8 and Figure 3 in the Supporting Information), especially over long interaction times (five, ten days). For Cu1 the points corresponding to the synthesized silica and the mixed $\mathrm{ZrO}_{2}-\mathrm{SiO}_{2}$ matrix are substantially coincident. This latter result can be ascribed to the higher reactivity of the Cu1 precursor, which presumably overcomes the effect of the matrix reactivity.

Effect of the temperature and type of thermal treatment: The effect of thermal treatment of the supporting matrices on the grafting efficiency of the carbamate was studied on the matrix with $\mathrm{Zr} / \mathrm{Si}$ molar ratio $=1: 2.5$ upon treatment at $600^{\circ} \mathrm{C}$ with both conventional and microwave heating, and at $1000^{\circ} \mathrm{C}$ with conventional heating, before the grafting experiments. The resulting mixed oxides were then made to react with the carbamato solution of $\mathbf{C u 1}$ for three days. Comparison of the samples treated at $600^{\circ} \mathrm{C}$ and $1000^{\circ} \mathrm{C}$ (Table 2) demonstrated that, when the temperature of thermal treatment of the matrix is increased, a lower proportion of copper oxide is anchored on the oxide surface: other conditions being equal, the sample ZS125 MF1000 Cu1-3 has a $\mathrm{Cu} / \mathrm{Si}$ ratio of 1:5.2, whereas the homologue ZS125 MF600 Cu1-3 treated at $600^{\circ} \mathrm{C}$ displays a ratio of 1:1.5.

This can be rationalized by assuming that the higher annealing temperatures promote the condensation of the $\mathrm{OH}$ groups on the surface of the oxide, as reported extensively
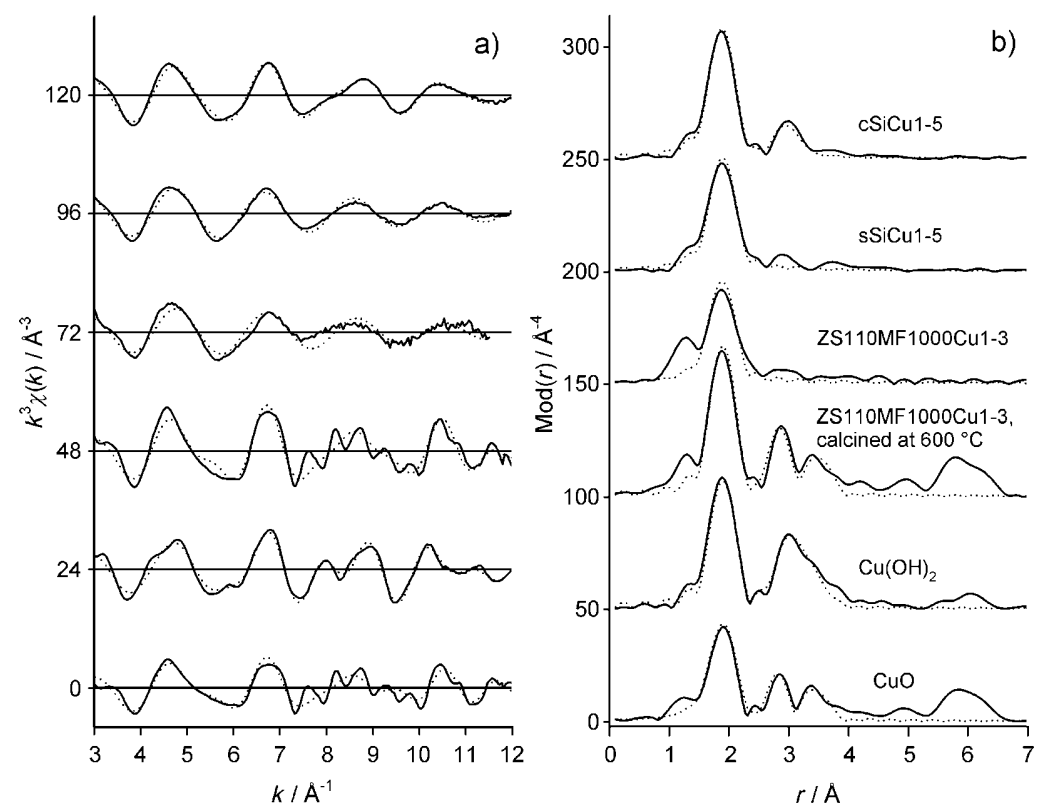

Figure 9. a) Experimental (solid line) and calculated (dotted line) EXAFS functions and b) their Fourier transforms for the functionalized samples cSi Cu1-5, sSiCu1-5, ZS110 MF1000 Cu1-3, ZS110 MF1000 Cu1-3 (calcined at $600^{\circ} \mathrm{C}$ ), and the references $\mathrm{Cu}(\mathrm{OH})_{2}$ and $\mathrm{CuO}$ measured at the $\mathrm{Cu}$ K-edge. Spectra have been shifted for 
in previous studies on these systems, ${ }^{[36-38]}$ thus yielding unreactive $\mathrm{Si}-\mathrm{O}-\mathrm{Si}$ groups, as evidenced by IR analysis also (vide supra).

There is a lower proportion of grafted copper in the samples treated with microwaves $(\mathrm{Cu} / \mathrm{Si}=1: 5.5)$ than in those treated conventionally $(\mathrm{Cu} / \mathrm{Si}=1: 1.5$; see Table 2$)$. This can again be explained by the earlier finding that samples treated conventionally display more Brønsted acidic $\mathrm{OH}$ groups. ${ }^{[53]}$

EXAFS and X-ray absorption near-edge structure (XANES) spectroscopy were applied to study the type and structure of the grafted copper species on the various matrices. ${ }^{[55,56]}$ We analyzed grafted matrices of commercial silica (cSi), synthesized silica (sSi), and the silica-zirconia matrices ZS110 MF1000, ZS125 MF1000, ZS125MF600, and ZS125MW600 (Table 3). Further EXAFS analyses of $\mathrm{Cu}-$ functionalized silica-zirconia materials were performed after an additional calcination step at $600^{\circ} \mathrm{C}$ for ZS110 MF1000 Cu1-3 and at $800^{\circ} \mathrm{C}$ for ZS125 MF1000 Cu13, ZS125MF600Cu1-3, and ZS125MW600Cu1-3. Table 4 summarizes the structural parameters determined by curvefitting analysis for all the samples. The EXAFS spectra and Fourier transform plots of selected functionalized samples and the references $\mathrm{CuO}$ and $\mathrm{Cu}(\mathrm{OH})_{2}$ are shown in Figure 9. The EXAFS results of the references $\mathrm{CuO}$ and $\mathrm{Cu}(\mathrm{OH})_{2}$ are in good agreement with the crystallographic data (Table 4). In $\mathrm{CuO}$ the copper atoms have a tetragonally distorted $\mathrm{Cu}(\mathrm{O})_{6}$ coordination with four oxygen neighbors at about $1.95 \AA$ and two axial oxygen ligands at $2.78 \AA . \mathrm{Cu}(\mathrm{OH})_{2}$ has a similar tetragonally distorted $\mathrm{Cu}(\mathrm{O})_{6}$ environment but with an axial $\mathrm{Cu}-\mathrm{O}$ distance of $2.63 \AA$. In the Fourier transforms of both compounds only the first oxygen shell at about $1.95 \AA$ can be seen (Figure 9b). The axial oxygen shells at $2.78 \AA$ and $2.63 \AA$ are not clearly visible. This can be attributed to a combination of large DebyeWaller factors and interference with oscillations from more distant shells. ${ }^{[57,58]}$ Accordingly, only the first oxygen shells were fitted, together with the copper shells.

The EXAFS spectra of the samples sSi Cu1-5 (Figure 9), ZS110 MF1000 Cu1-3 ZS125 MF1000 Cu1-3, ZS125 MF600 Cu1-3,
ZS125 MW600 Cu1-3 exhibit only one oxygen shell at a distance of about $1.94 \AA$. The corresponding coordination numbers are about 4 . These results are in agreement with a tetragonal oxygen coordination of the grafted copper atoms similar to that in $\mathrm{CuO}$ and $\mathrm{Cu}(\mathrm{OH})_{2}$. Furthermore, the absence of a second shell suggests that the copper is present as isolated copper atoms or as small amorphous $\mathrm{Cu}_{n} \mathrm{O}_{x}(\mathrm{OH})_{y}$ aggregates consisting of only a few atoms. These findings are also in accordance with the EPR analyses which show magnetically diluted $\mathrm{Cu}^{\mathrm{II}}$ centers with a tetragonal symmetry (vide supra).

Table 3. Matrix preparation and features

\begin{tabular}{lllll}
\hline Matrix & $\begin{array}{l}\text { Zr/Si } \\
\text { molar } \\
\text { ratio }\end{array}$ & $\begin{array}{l}\text { Annealing } \\
\text { treatment }\end{array}$ & $\begin{array}{l}\text { Annealing tem- } \\
\text { perature }\left[{ }^{\circ} \mathrm{C}\right]\end{array}$ & $\begin{array}{l}\text { Time of an- } \\
\text { nealing }[\mathrm{h}]\end{array}$ \\
\hline SSi & 0 & MF & 1000 & 4 \\
ZS110 MF1000 & $1: 10$ & MF & 1000 & 4 \\
ZS125 MF1000 & $1: 2.5$ & MF & 1000 & 4 \\
ZS125 MF600 & $1: 2.5$ & MF & 600 & 4 \\
ZS125 MW600 & $1: 2.5$ & MW & 600 & 1
\end{tabular}

[a] $\mathrm{MF}=$ conventional thermal treatment; $\mathrm{MW}=$ microwave treatment.

Table 4. Structural parameters from EXAFS studies of the functionalized samples and the reference compounds $\mathrm{CuO}$ and $\mathrm{Cu}(\mathrm{OH})_{2}$ measured at the $\mathrm{Cu} \mathrm{K}$-edge.

\begin{tabular}{|c|c|c|c|c|c|c|}
\hline Sample & $\mathrm{A}-\mathrm{Bs}^{[\mathrm{a}]}$ & $N^{[\mathrm{b}]}$ & $r^{[\mathrm{b}]}[\AA]$ & $r^{[\mathrm{b}]}[\AA] \mathrm{XRD}^{[\mathrm{c}]}$ & $\sigma^{[\mathrm{b}]}[\AA]$ & Fit index \\
\hline \multirow[t]{5}{*}{$\mathrm{CuO}^{[\mathrm{c}]}$} & $\mathrm{Cu}-\mathrm{O}$ & 4 & $1.95 \pm 0.02$ & $1.96^{[\mathrm{d}]}$ & $0.084 \pm 0.008$ & 40.28 \\
\hline & $\mathrm{Cu}-\mathrm{O}$ & 2 & - & $2.78^{[\mathrm{e}]}$ & - & \\
\hline & $\mathrm{Cu}-\mathrm{Cu}$ & 8 & $2.93 \pm 0.03$ & $2.99^{[\mathrm{d}]}$ & $0.136 \pm 0.020$ & \\
\hline & $\mathrm{Cu}-\mathrm{Cu}$ & 2 & $3.14 \pm 0.03$ & 3.18 & $0.074 \pm 0.011$ & \\
\hline & $\mathrm{Cu}-\mathrm{Cu}$ & 2 & $3.38 \pm 0.03$ & 3.42 & $0.092 \pm 0.014$ & \\
\hline \multirow[t]{4}{*}{$\mathrm{Cu}(\mathrm{OH})_{2}{ }^{[\mathrm{c}]}$} & $\mathrm{Cu}-\mathrm{O}$ & 4 & $1.95 \pm 0.02$ & $1.94^{[\mathrm{d}]}$ & $0.063 \pm 0.006$ & 19.84 \\
\hline & $\mathrm{Cu}-\mathrm{O}$ & 2 & - & $2.63^{[\mathrm{e}]}$ & - & \\
\hline & $\mathrm{Cu}-\mathrm{Cu}$ & 2 & $2.95 \pm 0.03$ & 2.95 & $0.077 \pm 0.012$ & \\
\hline & $\mathrm{Cu}-\mathrm{Cu}$ & 4 & $3.30 \pm 0.03$ & 3.34 & $0.122 \pm 0.018$ & \\
\hline \multirow[t]{2}{*}{ cSi Cu1-5 } & $\mathrm{Cu}-\mathrm{O}$ & $4.6 \pm 0.5$ & $1.94 \pm 0.02$ & - & $0.074^{[\mathrm{f}]}$ & 17.62 \\
\hline & $\mathrm{Cu}-\mathrm{Cu}$ & $2.2 \pm 0.3$ & $2.93 \pm 0.03$ & - & $0.112 \pm 0.017$ & \\
\hline \multirow[t]{2}{*}{ cSi Cu2-15 } & $\mathrm{Cu}-\mathrm{O}$ & $4.5 \pm 0.5$ & $1.94 \pm 0.02$ & - & $0.074^{[\mathrm{f}]}$ & 25.30 \\
\hline & $\mathrm{Cu}-\mathrm{Cu}$ & $2.8 \pm 0.4$ & $2.92 \pm 0.03$ & - & $0.122 \pm 0.018$ & \\
\hline sSi Cu1-5 & $\mathrm{Cu}-\mathrm{O}$ & $4.1 \pm 0.4$ & $1.95 \pm 0.02$ & - & $0.074^{[\mathrm{f}]}$ & 23.91 \\
\hline ZS110 MF1000 Cu1-3 & $\mathrm{Cu}-\mathrm{O}$ & $3.7 \pm 0.4$ & $1.94 \pm 0.02$ & - & $0.074^{[\mathrm{f}]}$ & 43.57 \\
\hline \multirow{4}{*}{$\begin{array}{l}\text { ZS110 MF1000 Cu1-3, } \\
\text { calcined at } 600^{\circ} \mathrm{C}\end{array}$} & $\mathrm{Cu}-\mathrm{O}$ & $4.4 \pm 0.4$ & $1.94 \pm 0.02$ & - & $0.059 \pm 0.006$ & 37.01 \\
\hline & $\mathrm{Cu}-\mathrm{Cu}$ & $8.6 \pm 1.3$ & $2.93 \pm 0.03$ & - & $0.128 \pm 0.019$ & \\
\hline & $\mathrm{Cu}-\mathrm{Cu}$ & $2.0 \pm 0.3$ & $3.16 \pm 0.03$ & - & $0.077 \pm 0.012$ & \\
\hline & $\mathrm{Cu}-\mathrm{Cu}$ & $1.9 \pm 0.3$ & $3.41 \pm 0.03$ & - & $0.077 \pm 0.012$ & \\
\hline ZS125 MF1000 Cu1-3 & $\mathrm{Cu}-\mathrm{O}$ & $4.1 \pm 0.4$ & $1.93 \pm 0.02$ & - & $0.074^{[\mathrm{f}]}$ & 60.18 \\
\hline $\begin{array}{l}\mathbf{Z S 1 2 5} \text { MF1000 Cu1-3, } \\
\text { calcined at } 800^{\circ} \mathrm{C}\end{array}$ & $\mathrm{Cu}-\mathrm{O}$ & $3.1 \pm 0.3$ & $1.90 \pm 0.02$ & - & $0.074^{[\mathrm{f}]}$ & 66.12 \\
\hline ZS125 MF600 Cu1-3 & $\mathrm{Cu}-\mathrm{O}$ & $4.4 \pm 0.4$ & $1.93 \pm 0.02$ & - & $0.074^{[\mathrm{f}]}$ & 31.65 \\
\hline $\begin{array}{l}\text { ZS125 MF600 Cu1-3, } \\
\text { calcined at } 800^{\circ} \mathrm{C}\end{array}$ & $\mathrm{Cu}-\mathrm{O}$ & $3.7 \pm 0.4$ & $1.92 \pm 0.02$ & - & $0.074^{[\mathrm{f}]}$ & 40.17 \\
\hline ZS125 MW600 Cu1-3 & $\mathrm{Cu}-\mathrm{O}$ & $4.0 \pm 0.4$ & $1.94 \pm 0.02$ & - & $0.074^{[\mathrm{f}]}$ & 34.70 \\
\hline $\begin{array}{l}\text { ZS125 MW600 Cu1-3, } \\
\text { calcined at } 800^{\circ} \mathrm{C}\end{array}$ & $\mathrm{Cu}-\mathrm{O}$ & $3.7 \pm 0.4$ & $1.93 \pm 0.02$ & - & $0.074^{[\mathrm{f}]}$ & 41.56 \\
\hline
\end{tabular}

[a] Absorber (A)-backscatterer (Bs). [b] Coordination number $N$, interatomic distance $r$, and Debye-Waller factor $\sigma$. Estimated errors: $\pm 1 \%$ for distances; $\pm 10 \%$ for coordination numbers and Debye-Waller factors of shells with $r<2.5 \AA ; \pm 15 \%$ for coordination numbers and Debye-Waller factors of shells with $r>2.5 \AA$. [c] The fixed multiplicities and crystallographic distances were taken from ref. [59] for $\mathrm{CuO}$ and ref. [60] for $\mathrm{Cu}(\mathrm{OH})_{2}$. [d] Averaged values. [e] Not fitted. [f] Fixed during fitting $(0.074 \AA$ is the average of the Debyeand Waller factors from the oxygen shells in $\mathrm{CuO}$ and $\left.\mathrm{Cu}(\mathrm{OH})_{2}\right)$. 
Samples cSi Cu1-5 (Figure 9) and cSi Cu2-15 exhibit additionally a $\mathrm{Cu}$ shell at a distance of about $2.93 \AA$, which indicates the formation of bigger or less disordered $\mathrm{Cu}_{n} \mathrm{O}_{x}(\mathrm{OH})_{y}$ aggregates than in the samples with only one oxygen shell. However, the absence of Fourier components beyond $3 \AA$ indicates that there is no long-range order and, hence, that the aggregates are still small and amorphous.

The EXAFS spectrum of sample ZS110MF1000Cu1-3 was also measured after calcination at $600^{\circ} \mathrm{C}$, when it shows a long-range order similar to that of bulk $\mathrm{CuO}$ (Figure 9). The fitted interatomic distances and coordination numbers confirm the CuO-like structure of the grafted copper species (Table 4). This is in agreement with the XRD, EPR, and TEM results which already revealed the presence of nanosized $\mathrm{CuO}$ particles after calcination at $600^{\circ} \mathrm{C}$. For the samples ZS125 MF1000 Cu1-3, ZS125MF600Cu1-3, and ZS125MW600 Cu1-3 the local structure does not change upon calcination at $800^{\circ} \mathrm{C}$. There is still only one oxygen shell with a coordination number of about 4 . This means that the fine dispersion of the copper species is retained during calcination. Agglomeration and formation of bigger $\mathrm{CuO}$ particles does not take place. Figure 10 shows the XANES region of the samples cSiCu1-5 and ZS110 MF1000 Cu1-3 (as prepared, and calcined at $600^{\circ} \mathrm{C}$ ) along with the references $\mathrm{Cu}_{2} \mathrm{O}, \mathrm{CuO}$, and $\mathrm{Cu}(\mathrm{OH})_{2}$. The spectrum of $\mathrm{Cu}_{2} \mathrm{O}$ exhibits a strong pre-edge peak $(1 \mathrm{~s} \rightarrow 4 \mathrm{p}$ transition) at $8984 \mathrm{eV}$, which is characteristic for $\mathrm{Cu}^{\mathrm{I}}$ compounds. ${ }^{[57,61,62]}$ The XANES spectrum of $\mathrm{CuO}$ has the following features: in the pre-edge region there is a low-inten-

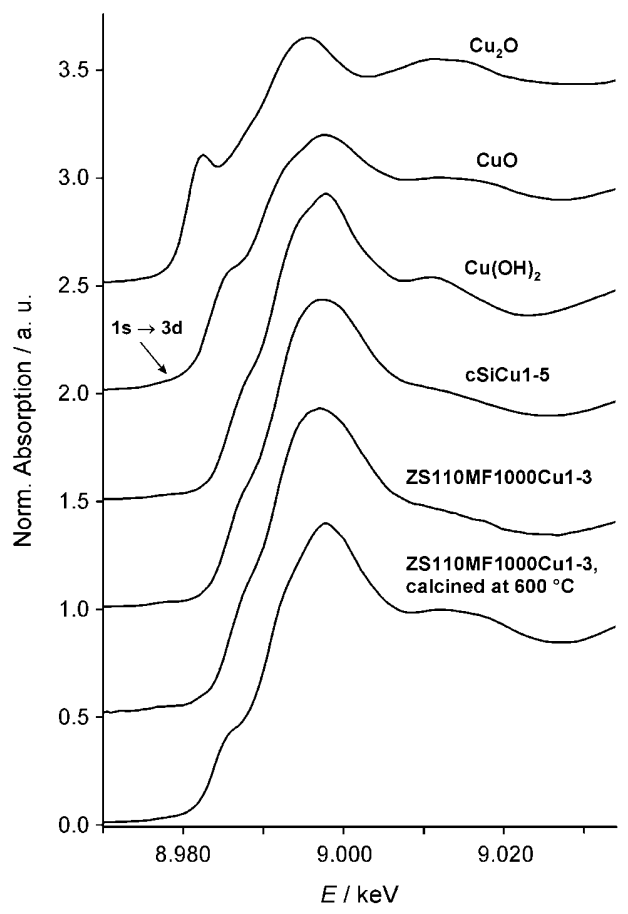

Figure 10. Normalized $\mathrm{Cu}$ K-edge XANES spectra of cSiCu1-5, ZS110 MF1000 Cu1-3, ZS110 MF1000 Cu1-3 (calcined at $600^{\circ} \mathrm{C}$ ), and the references $\mathrm{Cu}_{2} \mathrm{O}, \mathrm{CuO}$, and $\mathrm{Cu}(\mathrm{OH})_{2}$. Spectra have been shifted for clarity. sity $1 \mathrm{~s} \rightarrow 3 \mathrm{~d}$ transition at about $8979 \mathrm{eV}$, which is typical of $\mathrm{Cu}^{\mathrm{II}}$ compounds. ${ }^{[63,64]}$ In addition, there are two peaks along the rising edge between the pre-edge region and the absorption maximum. ${ }^{[62,63]}$ The first peak at about $8986 \mathrm{eV}$ is attributed to a $1 \mathrm{~s} \rightarrow 4 \mathrm{p}$ transition with shakedown contributions and the second peak at about $8993 \mathrm{eV}$ is assigned to a normal $1 \mathrm{~s} \rightarrow 4 \mathrm{p}$ transition. Mainly, the transition at $8986 \mathrm{eV}$ is seen as a distinctive shoulder inside the edge, which is characteristic for tetragonal $\mathrm{Cu}^{\mathrm{II}}$ compounds. For $\mathrm{Cu}(\mathrm{OH})_{2}$ this shoulder is weaker because the tetragonal distortion is less than in $\mathrm{CuO}$.

The XANES spectra of the samples cSiCu1-5 and ZS110 MF1000 Cu1-3 indicate that the grafted copper atoms have an oxidation state of + II because there is no strong pre-edge peak at $8984 \mathrm{eV}$ characteristic of $\mathrm{Cu}^{\mathrm{I}}$. In addition, the edge jumps of the samples are located at energy values typical of $\mathrm{Cu}^{\mathrm{II}}$. Further evidence for the oxidation state of + II is the presence of the weak $1 \mathrm{~s} \rightarrow 3 \mathrm{~d}$ transition at $9879 \mathrm{eV}$. In comparison to the XANES region of $\mathrm{CuO}$, the shoulder of the $1 \mathrm{~s} \rightarrow 4 \mathrm{p}$ transition with shakedown contributions is much weaker for the spectra of cSiCu1-6 and ZS110 MF1000 Cu1-3. Rather, the intensity of this shoulder is comparable to that of $\mathrm{Cu}(\mathrm{OH})_{2}$, indicating that the grafted copper atoms have a tetragonal oxygen coordination similar to that in $\mathrm{Cu}(\mathrm{OH})_{2}$. All the other functionalized samples (not shown in Figure 9) exhibit similar XANES spectra to cSi Cu1-5 and ZS110 MF1000 Cu1-3, and thus have the same local structure also. For the calcined sample ZS110 MF1000 Cu1-3 the intensity of the $1 \mathrm{~s} \rightarrow 4 \mathrm{p}$ shakedown transition is comparable to that of $\mathrm{CuO}$. This proves the presence of $\mathrm{CuO}$ particles, in agreement with the EXAFS results.

\section{Conclusions}

The use of suitably optimized silica-zirconia matrices to anchor copper $N, N$-dialkylcarbamato precursors, followed by thermal treatment, was proven to be an effective route to achieve the chemical implantation of $\mathrm{CuO}$ nanoclusters. The experimental parameters (nature, composition, and heat treatment of the supporting oxide, nature of the precursors, grafting time) play a remarkable role in determining the amount of the anchored nanosized oxide. In particular, it was shown that the synthesized silica-zirconia matrix realizes the highest anchoring efficiency, which can be ascribed to a higher acidity of the hydroxyl groups on the surface of the mixed-oxide matrix. Also the nature of the $\mathrm{R}$ group of the carbamato precursor affects the amount of immobilized copper. Time influences the grafting efficiency strongly; however, this effect is less evident for the silica-based matrices, where a smoother dependence of the $\mathrm{Cu} / \mathrm{Si}$ atomic ratio on time is observed. In the as-prepared samples the copper is present as isolated copper atoms or as small amorphous $\mathrm{Cu}_{n} \mathrm{O}_{x}(\mathrm{OH})_{y}$ aggregates consisting of only a few atoms. Additional calcination of the sample ZS110 MF1000Cu1-3 at $600^{\circ} \mathrm{C}$ yields $\mathrm{CuO}$ nanoparticles on the surface of the silica- 
zirconia matrix. This is not observed for the samples ZS125 MF1000 Cu1-3, ZS125MF600 Cu1-3, and ZS125MW600Cu1-3. Here, the fine dispersion of the copper species, observed in the as-prepared samples, is retained during calcination. Agglomeration and formation of $\mathrm{CuO}$ nanoparticles does not take place.

The optimized procedure can be considered a controlled and effective approach to the functionalization of oxide matrices with nanostructured metal oxides. Due to the wide availability of different metal $N, N$-dialkylcarbamato precursors, the procedure described could pave the way to a further modification of oxide surfaces by chemical implantation of metal oxide nanoparticles. In particular, the route developed could be used advantageously to address the synthesis of $\mathrm{ZnO}$ or $\mathrm{TiO}_{2}$ nanoparticles supported on silica-zirconia matrices, which are also interesting materials for catalysis and sensing.

A further interesting implementation of the method would rely either a) on the preparation and use of mixed $N, N$-dialkylcarbamato precursors, which would make it possible to prepare mixed-oxide nanoparticles supported on the oxide matrix, or b) on the preparation of mixtures of $\mathrm{N}, \mathrm{N}$ dialkylcarbamato precursors to prepare different oxide nanoparticles dispersed on the mixed matrix. Use of cobalt or manganese carbamates and careful choice of the experimental conditions to control their evolution would, for instance, enable the preparation of magnetic oxide nanoparticles supported on oxide matrices.

For the preparation of supported nanoparticles the approach presented here has advantages over other synthetic routes, such as CVD or sol-gel methods, ${ }^{[65]}$. Firstly, as outlined in the Introduction and in the Experimental Section, the presence of several independent experimental parameters (nature and molar ratios of the precursors, nature and temperature of thermal annealing, grafting time, nature of the matrix) makes the method highly versatile, also enabling controlled tuning of the composition and of the microstructure of the nanostructured materials obtained. The approach, although involving several synthetic steps, allows very good control on a) the composition of the final material (by careful choice of the precursors), b) the amount of supported materials (by changing the grafting times and supporting matrix), and c) the size of the oxide nanostructures (by variation of the annealing temperature). Last but not least, the seeded growth of the nanoparticles starting from molecular complexes makes it possible to control formation of nanoparticles with narrow size dispersity, thus demonstrating the effectiveness of the molecule-to-material concept. A switch from $N, N$-dialkylcarbamato to $N, N$-dialkyldithiocarbamato precursors would also represent an effective and original route to the tailored preparation of metal sulfide nanoparticles supported on mixed oxides, which could be interesting for optical or nonlinear optical applications.

\section{Experimental Section}

Chemicals: Due to the high moisture sensitivity of the precursors, all preparations were carried out in standard Schlenk tubes under an argon atmosphere, unless otherwise stated. Amines (diisopropylamine $(\mathrm{NHiPr})$ and diallylamine ( $\left.\mathrm{NHAll}_{2}\right)$ ) and heptane (Aldrich) were distilled over the appropriate drying agent under an argon atmosphere. $\mathrm{CuCl}_{2} \cdot \mathrm{H}_{2} \mathrm{O}(\mathrm{Al}-$ drich), $99.8 \%$ purity, was dried before use by heating at $140{ }^{\circ} \mathrm{C}$ in vacuo for three days. $\mathrm{CO}_{2}, 99.99 \%$ purity, was purchased from Air Liquide and used as received. Tetrabutoxozirconium(IV), $80 \%$ in butanol (Strem Chemicals), methacryloxypropyltrimethoxysilane (MAPTMS) purchased from ABCR GmbH, Germany, dry tetrahydrofuran, and dry toluene (Aldrich) were used as received or distilled before use, and stored under argon. Methacrylic acid, 99\% (Aldrich), was distilled under reduced pressure and stored under argon. Dibenzoyl peroxide (Aldrich) was used as a thermal initiator for the polymerization reactions of MAPTMS.

\section{Procedures}

$\left[\mathrm{Cu}\left(\mathrm{O}_{2} \mathrm{CNiPr}_{2}\right)_{2}\right](\mathbf{C u 1})$ : $\mathbf{C u 1}$ was prepared as reported by Agostinelli et al. ${ }^{[13]}$ An $\mathrm{NHiPr}_{2}$ solution $(7 \mathrm{~mL}, 49.9 \mathrm{mmol})$ in heptane $(25 \mathrm{~mL})$ was saturated with $\mathrm{CO}_{2}$. Anhydrous $\mathrm{CuCl}_{2}(1.50 \mathrm{~g}, 11.2 \mathrm{mmol})$ was added, the suspension was stirred for $24 \mathrm{~h}$ at RT, and the system was saturated periodically with $\mathrm{CO}_{2}$; a blue solution and a colorless precipitate of $\left[\mathrm{NH}_{2} i \mathrm{Pr}_{2}\right] \mathrm{Cl}$ were obtained. The suspension was filtered and the solvent was removed from the filtered solution in vacuo at RT, giving the blue copper-containing product. Yield 70\%; FTIR (Nujol): $\tilde{v}=1575,1560$, 1480, 1464, 1382, 1352 [brs, $\mathrm{NCO}_{2}$ ), $1260-1030 \mathrm{~cm}^{-1}$ (brs, C-N); elemental analysis calcd $(\%)$ for $\mathbf{C u 1}\left[\mathrm{Cu}\left(\mathrm{O}_{2} \mathrm{CNiPr}\right)_{2}\right]$ : $\mathrm{C} 47.8, \mathrm{H}$ 8.0, N 8.0; found: C 46.5, $\mathrm{H} 7.8, \mathrm{~N} 7.9$.

$\left[\mathrm{Cu}\left(\mathrm{O}_{2} \mathrm{CNAll}_{2}\right)_{2}\right](\mathbf{C u 2})$ and $\left[\mathrm{Cu}_{4} \mathrm{Cl}_{4}\left(\mathrm{NHAll}_{2}\right)_{4}\right]_{n}(\mathbf{C u 3}): \mathbf{C u} 2$ was obtained by a procedure analogous to that used for Cu1. An $\mathrm{NHAll}_{2}$ solution $(7 \mathrm{~mL}, 56.8 \mathrm{mmol})$ in heptane $(25 \mathrm{~mL})$ was saturated with $\mathrm{CO}_{2}$ at atmospheric pressure. $\mathrm{CuCl}_{2}(1.50 \mathrm{~g}, 11.2 \mathrm{mmol})$ was added and the suspension was stirred for $24 \mathrm{~h}$. An intense blue-violet solution and a colorless precipitate were obtained. The filtered solution was allowed to stand for $3 \mathrm{~h}$ at RT, during which the formation of colorless needle-like crystals $(\mathbf{C u 3})$, $\left[\mathrm{Cu}_{4} \mathrm{Cl}_{4}\left(\mathrm{NHAll}_{2}\right)_{4}\right]_{n}$, suitable for single-crystal X-ray analysis was observed. ${ }^{[6]}$ This product, at present under study, was separated by filtration and washed once with heptane $(30 \mathrm{~mL})$.

Cu2 was obtained from the filtrate after removal of the solvent in vacuo (33\% yield). FTIR (solution in heptane): $\tilde{v}=3079\left(\mathrm{~m}, v_{\mathrm{s}}(=\mathrm{C}-\mathrm{H})\right), 2960$ $\left[\mathrm{s}, v_{\mathrm{as}}\left(\mathrm{CH}_{3}\right), v_{\mathrm{as}}\left(\mathrm{CH}_{2}\right)\right], 2860\left[\mathrm{~s}, v_{\mathrm{s}}\left(\mathrm{CH}_{3}\right), v_{\mathrm{s}}\left(\mathrm{CH}_{2}\right)\right], 1460\left[\mathrm{~m}, \delta\left(\mathrm{CH}_{2}\right)\right], 1643$ $\left[\mathrm{m}, v_{\mathrm{s}}(\mathrm{C}=\mathrm{C})\right], 1378\left[\mathrm{~m}, \delta\left(\mathrm{CH}_{3}\right)\right], 1602,1577,1395 \mathrm{~cm}^{-1}\left[\mathrm{~m}, v \mathrm{NCO}_{2}\right]$; elemental analysis calcd $(\%)$ for $\mathbf{C u} 2\left[\mathrm{Cu}\left(\mathrm{O}_{2} \mathrm{CNAll}_{2}\right)_{2}\right]$ : C 48.9, $\mathrm{H} 5.9, \mathrm{Cu}$ 18.5, N 8.2; found: C 47.4, H 6.6, Cu 18.8, N 9.2.

Inorganic matrices: For the grafting experiments, six different kinds of matrices were used: a commercial silica for flash chromatography (cSi) and five synthesized matrices. The matrices sSi, ZS110MF1000, ZS125MF1000, ZS125MF600, and ZS125MW600 were prepared as reported previously ${ }^{[36-38]}$ by copolymerization of the oxozirconium derivative $\mathrm{Zr}_{4} \mathrm{O}_{2}(\mathrm{OMc})_{12} \quad(\mathrm{OMc}=\text { methacrylate })^{[40]}$ with prehydrolyzed MAPTMS followed by thermal treatment in a conventional muffle or in a microwave oven. The zirconium oxocluster was prepared as described in ref. [67]. Table 3 summarizes the $\mathrm{Zr} / \mathrm{Si}$ molar ratios used for the preparation of the matrices (according to the nominal composition of the solution) and the annealing conditions.

Chemical grafting: All matrices were heated at $160^{\circ} \mathrm{C}$ in vacuo for $10 \mathrm{~h}$ to remove the physisorbed water. Although they had already been treated at $600{ }^{\circ} \mathrm{C}$ and $1000^{\circ} \mathrm{C}$, respectively, they were stored for some days before the grafting experiments, and this could have caused their (at least partial) rehydration. Consequently, to avoid concurrent reaction of water with the carbamates, the matrices were heated again in vacuo. In a typical grafting experiment, a solution $(10 \mathrm{~mL}, 0.5 \mathrm{M})$ of a copper precursor ( Cu1 or Cu2) in heptane was added to the matrix ( $0.9 \mathrm{~g})$ under an argon atmosphere. The suspension was stirred for the time reported in Table 5, then filtered. To remove the adsorbed unreacted copper complex, the product was washed with heptane $(3 \times 10 \mathrm{~mL})$ and $\mathrm{Et}_{2} \mathrm{O}(3 \times 10 \mathrm{~mL})$, suspended in heptane $(20 \mathrm{~mL})$, and recovered by filtration. Table 5 explains 
Table 5. Sample labeling and parameters of the grafting experiments.

\begin{tabular}{lcll}
\hline Sample $^{[a]}$ & $\begin{array}{l}\text { Grafting } \\
\text { time }[\mathrm{d}]\end{array}$ & $\begin{array}{l}\mathrm{Cu} \\
\text { precursor }\end{array}$ & Matrix \\
\hline cSiCu1-1 & 1 & Cu1 & cSi \\
cSiCu1-5 & 5 & Cu1 & cSi \\
cSiCu1-15 & 15 & Cu1 & cSi \\
sSiCu1-5 & 5 & Cu1 & sSi \\
ZS110 MF1000 Cu1-3 & 3 & Cu1 & ZS110MF1000 \\
ZS110MF1000 Cu1-5 & 5 & Cu1 & ZS110MF1000 \\
ZS110MF1000 Cu1-10 & 10 & Cu1 & ZS110MF1000 \\
ZS125MF1000 Cu1-3 & 3 & Cu1 & ZS125MF1000 \\
ZS125 MF600Cu1-3 & 3 & Cu1 & ZS125MF600 \\
ZS125MW600Cu1-3 & 3 & Cu1 & ZS125MW600
\end{tabular}

[a] The first two parts of a sample label specify the matrix ( $\mathrm{Zr}: \mathrm{Si}$ molar ratio, type of oven, annealing temperature); the third part refers to the parameters involved in the grafting experiment (nature of the precursor, grafting time). For instance, sample ZS110 MF1000 Cu2-10 was prepared from a silica-zirconia matrix with a $\mathrm{Zr} / \mathrm{Si}$ molar ratio of 1:10 which was treated in a muffle (MF) oven at $1000^{\circ} \mathrm{C}$. Grafting was performed with the $\mathbf{C u 2}$ precursor for ten days.

the labeling system, and gives the copper precursor, the grafting time, and the type of matrix for the samples discussed in this paper. A complete list of all the samples prepared is reported in the Supporting Information (Table S4). Selected functionalized samples were further annealed at $600{ }^{\circ} \mathrm{C}$ for $4 \mathrm{~h}$ to study their crystallization behavior and to promote the formation of $\mathrm{CuO}$ nanoparticles grafted on the silica and on the silica-zirconia matrices.

Characterization of the materials: Transmission FTIR spectra were recorded at RT with a Nicolet Nexus 870 FTIR spectrophotometer in the range $400-4000 \mathrm{~cm}^{-1}$, by averaging 32 scans, with a resolution of $4 \mathrm{~cm}^{-1}$. The solid samples were ground finely in a mortar and analyzed after dispersion in pellets of spectroscopic-grade $\mathrm{KBr}$ (Merck AG, Germany).

The solids were investigated by XPS with a Perkin-Elmer $\varphi$ 5600ci instrument using standard $\mathrm{AlK}_{\alpha}$ radiation $(1486.6 \mathrm{eV})$ operating at $350 \mathrm{~W}$. The working pressure was $\leq 5 \times 10^{-8} \mathrm{~Pa}\left(\approx 10^{-11}\right.$ torr $)$. The calibration was based on the binding energy (BE) of the $\mathrm{Au} 4 \mathrm{f}_{7 / 2}$ line at $83.9 \mathrm{eV}$ with respect to the Fermi level. The standard deviation for the $\mathrm{BE}$ values was $0.15 \mathrm{eV}$. The reported BEs were corrected for the BE charging effects, assigning the $\mathrm{BE}$ value of $284.6 \mathrm{eV}$ to the $\mathrm{C} 1 \mathrm{~s}$ line. For the calcined samples, the charging effects were corrected by assigning the value of silica $(103.6 \mathrm{eV})$ to the Si $2 \mathrm{p}$ region ${ }^{[42]}$ Survey scans were obtained in the $0-$ $1350 \mathrm{eV}$ range (pass energy $187.5 \mathrm{eV}, 1.0 \mathrm{eV} / \mathrm{step}, 25 \mathrm{~ms} / \mathrm{step}$ ). Detailed scans $(58.7 \mathrm{eV}$ pass energy, $0.1 \mathrm{eV} / \mathrm{step}, 50-150 \mathrm{~ms} / \mathrm{step})$ were recorded for the O 1s, C 1s, Zr 3p, Zr 3d, Si 2p, Cu 2p, and Cu LMM regions. The atomic composition, after a Shirley-type background subtraction, ${ }^{[6]}$ was evaluated using sensitivity factors supplied by Perkin-Elmer ${ }^{[40]}$ Charge effects were partially compensated by using a charge neutralizer (flood gun). Peak assignment was carried out according to literature data. ${ }^{[15,23,24,40,41,69]}$

TGA experiments were performed in an open alumina pan on samples of about $15 \mathrm{mg}$ with an SDT 2960 thermobalance (TA Instruments) in the range $25-1100^{\circ} \mathrm{C}$ under an air flux of $70 \mathrm{~cm}^{3} \mathrm{~min}^{-1}$, and with a heating rate of $20^{\circ} \mathrm{Cmin}^{-1}$.

Nitrogen adsorption-desorption isotherms were determined at $77 \mathrm{~K}$ using an adsorption porosimeter (Micromeritics, ASAP 2010/2020) on samples outgassed for $6 \mathrm{~h}$ at $473 \mathrm{~K}$ in vacuo before analysis. The BET surface area was evaluated using adsorption data in the pressure range $0.05-$ $0.2 \mathrm{~atm} .{ }^{[70]}$ The total pore volume was estimated from the amount of gas adsorbed at a relative pressure of about $0.99 \mathrm{~atm}$.

XRD data were collected with a Bruker D8 Advance Diffractometer equipped with a Göbel mirror and a $\mathrm{Cu}-\mathrm{K}_{\alpha}$ source $(40 \mathrm{kV}, 40 \mathrm{~mA})$. The angular accuracy was $0.001^{\circ}$ and the angular resolution was better than $0.01^{\circ}$.
For TEM, a drop of a suspension of the sample in acetone was deposited on a carbon-coated 400-mesh copper grid in a Zeiss EM 912 OMEGA instrument operating at an acceleration voltage of $120 \mathrm{kV}$.

The $\mathrm{X}$ band continuous-wave EPR spectra of grafted $\left[\mathrm{Cu}\left(\mathrm{O}_{2} \mathrm{CN} i \mathrm{Pr}_{2}\right)_{2}\right]$ for samples before and after annealing in air were recorded at $123 \mathrm{~K}$ on a Bruker EMX instrument, using $10 \mathrm{~mW}$ microwave power and $10 \mathrm{G}$ modulation amplitude. The temperature was controlled with an Oxford cryostat. The $g$ values were standardized with diphenylpicrylhydrazyl (DPPH). The number of paramagnetic centers (spins/gram) was calculated by calibration curves of the resonance area of $\mathrm{Cu}\left(\mathrm{NO}_{3}\right)_{2} \cdot 0.5 \mathrm{H}_{2} \mathrm{O}$ in frozen ethylene glycol/water solutions with an accuracy estimated at $\pm 10 \%$

The thermal treatments were performed under flowing dry air in a quartz apparatus suitable for both gas-flow and EPR measurements, up to $800^{\circ} \mathrm{C}$ in steps of $100^{\circ} \mathrm{C}(30 \mathrm{~min})$.

The XANES and EXAFS measurements at the Cu K-edge $(8979 \mathrm{eV})$ were performed at the beamline XAS at ANKA, Angstroemquelle Karlsruhe, Germany. The samples were measured in transmission mode with a $\mathrm{Si}(111)$ double-crystal monochromator. Measurements of the sample ZS125MF1000 Cu1-3 (as prepared, and calcined at $800^{\circ} \mathrm{C}$ ) had to be carried out in fluorescence mode because of the low copper concentration in these two samples. The spectra were collected with a seven-element germanium fluorescence detector at beamline X1 of the Hamburger Synchrotronstrahlungslabor (HASYLAB) at DESY in Hamburg, Germany. The sample powders were embedded in a cellulose matrix and pressed into pellets. All experiments were carried out under ambient conditions at $21^{\circ} \mathrm{C}$. Energy calibration was performed with a copper metal foil Data evaluation started with the removal of background absorption from the experimental spectrum by subtraction of a Victoreen-type polynomial which was fitted to the pre-edge region of the spectrum. After normalization of the spectrum, the program AUTOBK ${ }^{[7]}$ was used to remove the post-edge background and to isolate the EXAFS function $\chi(k)$. Curve fitting analysis of the EXAFS function was performed according to the curved wave formalism of the program EXCURV98. ${ }^{[72]}$ The amplitude reduction factor (AFAC) was fixed at 0.8 .

\section{Acknowledgements}

Simone Mascotto is gratefully acknowledged for the synthesis of the silica-zirconia matrix, Dr. Lidia Armelao and The Nanofabrication Laboratory-The University of Western Ontario (London, Canada) for SEM analysis, and Dr. Antonella Glisenti for helpful discussions and suggestions. The University of Padova, the Italian National Research Council (CNR), the Deutsche Forschungsgemeinschaft (DFG) and the MaxPlanck Gesellschaft, Germany, are acknowledged for financial support. The Ateneo Italo Tedesco, Trento, Italy, and the Deutsche Akademische Austauschdienst (DAAD), Bonn, Germany, are gratefully acknowledged for funding the mobility of E.W., M.R., S.M., and S.G. in the framework of the Vigoni Programme. Dr. G. Pace is gratefully acknowledged for the thermal analyses. The authors also acknowledge the ANKA Angstroemquelle Karlsruhe for the provision of beamtime and thank Dr. Stefan Mangold for assistance in the use of the XAS beamline. We also thank HASYLAB at DESY, Hamburg, for their support of synchrotron radiation and Dr. Adam Webb for assistance at beamline X1. Dr. Roberta Saini and Dr. Giuseppe Pace are gratefully acknowledged for TGA analyses.

[1] F. Cinquini, C. Di Valentin, E. Finazzi, L. Giordano, G. Pacchioni, Theor. Chem. Acc. 2007, 117, 827-845.

[2] P. Braunstein, H.-P. Korman, W. Meyer-Zaika, R. Pugin, G. Schmid, Chem. Eur. J. 2000, 6, 4637-4646.

[3] M. A. White, J.A. Johnson, J. T. Koberstein, N. J. Turro, J. Am. Chem. Soc. 2006, 128, 11356-11357.

[4] H. H. Kung, Transition Metal Oxides: Surface Chemistry and Catalysis, Elsevier, Amsterdam, 1989. 
[5] a) A. Vittadini, A. Selloni, J. Phys. Chem. B 2004, 108, 7337; b) A. Vittadini, M. Casarin, A. Selloni, J. Phys. Chem. B 2004, 108, 1652; c) A. Vittadini, M. Casarin, A. Selloni, Theor. Chem. Acc. 2007, 117, 663-671; d) G. C. Bond, S. F. Tahir, Appl. Catal. 1991, 71, 1.

[6] a) K.-W. Yao, S. Jaenicke, J.-Y Lin, K. L. Tan, Appl. Catal. B 1998 , 16, 291-301; b) S. Boutet, B. Jousseaume, T. Toupance, M. Biesemans, R. Willem, C. Labrugere, L. Delattre, Chem. Mater. 2005, 17, $1803-1811$.

[7] T. J. Marks, Acc. Chem. Res. 1992, 25, 57.

[8] F. Quignard, C. Lecuyer, C. Bougault, F. Lefebvre, A. Choplin, D. Olivier, J. M. Basset, Inorg. Chem. 1992, 31, 928.

[9] C. Nedez, A. Choplin, J. M. Basset, E. Benazzi, Inorg. Chem. 1994, 33, 1094.

[10] F. Hugues, J. M. Basset, Y. Ben Taarit, A. Choplin, M. Primet, D. Rojas, A. K. Smith, J. Am. Chem. Soc. 1982, 104, 7020.

[11] Q. Zhuang, A. Fukuoka, T. Fujimoto, K. Tanaka, M. Ichikawa, J. Chem. Soc. Chem. Commun. 1991, 745.

[12] a) L. Abis, D. B. Dell'Amico, L. Abis, F. Calderazzo, R. Caminiti, F. Garbassi, S. Ianelli, G. Pelizzi, P. Robino, A. Tomei, J. Mol. Catal. A 1996, 108, L113; b) L. Abis, F. Calderazzo, C. Maichle-Mössmer, G. Pampaloni, J. Strähle, G. Tripepi, J. Chem. Soc. Dalton Trans. 1998, 841 ; c) L. Abis, D. B. Dell'Amico, C. Busetto, F. Calderazzo, R. Caminiti, C. Ciofi, F. Garbassi, G. Masciarelli, J. Mater. Chem. 1998, 8, 751; d) L. Abis, D. Belli Del'Amico, C. Busetto, F. Calderazzo, R. Caminiti, F. Garbassi, A. Tomei, J. Mater. Chem. 1998, 8, 2855; e) U. Baisch, D. Belli Dell'Amico, F. Calderazzo, L. Labella, F. Marchetti, Eur. J. Inorg. Chem. 2004, 1219; f) L Abis, L. Armelao, D. Belli Dell'Amico, F. Calderazzo, F. Garbassi, A. Merigo, E. A. Quadrelli $J$. Chem. Soc. Dalton Trans. 2001, 2704; g) D. Belli Dell'Amico, F. Calderazzo, L. Labella, F. Marchetti, G. Pampaloni, Inorg. Chem. Commun. 2002, 5, 733; h) A. Belforte, D. Belli Dell'Amico, F. Calderazzo, U. Giurlani, L. Labella, Gazz. Chim. Ital. 1993, 123, 119; i) D. Belli Dell'Amico, F. Calderazzo, L. Labella, F. Marchetti, G. Pampaloni, Chem. Rev. 2003, 103, 3857; j) D. Belli Dell'Amico, F. Calderazzo, S. Ianelli, L. Labella, F. Marchetti, G. Pelizzi, J. Chem. Soc. Dalton Trans. 2000, 4339; k) D. Belli Dell'Amico, C. Bradicich, F. Calderazzo, A. Guarini, L. Labella, F. Marchetti, A. Tomei, Inorg. Chem. 2002, 41, 2814; 1) U. Abram, D. Belli Dell'Amico, F. Calderazzo, S. Kaskel, L. Labella, F. Marchetti, R. Rovai, J. Strähle, J. Chem. Soc. Chem. Commun. 1997, 1941; m) D. Belli. Dell'Amico, F. Calderazzo, L. Labella, C. M. Mössmer, J. Strähle, J. Chem. Soc. Chem. Commun. 1994, 1555.

[13] E. Agostinelli, D. Belli Dell'Amico, F. Calderazzo, D. Fiorani, G. Pelizzi, Gazz. Chim. Ital. 1988, 118, 729.

[14] D. Belli Dell'Amico, F. Calderazzo, S. Farnocchi, L. Labella, F. Marchetti, Inorg. Chem. Commun. 2002, 5, 848.

[15] A. Gervasini, P. Carniti, S. Bennici, C. Messi, Chem. Mater. 2007, 19, 1319.

[16] M. Anpo, T. Nomura, T. Kitao, E. Giamello, D. Murphy, M. Che, M. A. Fox, Res. Chem. Intermed. 1991, 15, 225.

[17] L. Li, J. N. Armor, Appl. Catal. B 1992, 1, L21.

[18] J. Blanco, P. Avila, S. Suarez, M. Yates, J. A. Martin, L. Marzo, C. Knapp, Chem. Eng. J. 2004, 97, 1-9.

[19] A. Dandekar, M. A. Vannice, Appl. Catal. B 1999, 22, 179.

[20] X. Wang, W. Hou, X. Wang, Q. Yan, Appl. Catal. B 2002, 35, 185.

[21] K.-W. Yao, S. Jaenicke, J.-Y Lin, K. L. Tan, Appl. Catal. B 1998, 16, 291-301.

[22] F. Boccuzzi, S. Coluccia, G. Martra, N. Ravasio, J. Catal. 1999, 184, 316.

[23] J. Morales, A. Caballero, J. P. Holgado, J. P. Espinos, A. R. Gonzalez-Elipe, J. Phys. Chem. B 2002, 106, 10185.

[24] A. Gervasini, M. Manzoli, G. Martra, A. Ponti, N. Ravasio, L. Bordelli, F. Zaccheria, J. Phys. Chem. B 2006, 110, 15

[25] F. Boccuzzi, S. Coluccia, S. Martra, N. Ravasio, J. Catal. 1997, 165, 129.

[26] I. A. Fisher, A. T. Bell, J. Catal. 1999, 184, 357.

[27] J. B. Miller, E. Ko, J. Catal. 1996, 159, 58.

[28] K. W. Terry, C. G. Lugmair, T. D. Tilley, J. Am. Chem. Soc. 1997, $119,9745$.
[29] M. Itoh, H. Hattori, K. J. Tanabe, J. Catal. 1974, 35, 225.

[30] H. J. M. Bosman, E. C. Kruissink, J. Vanderspoel, F. Vandenbrink, J. Catal. 1994, 148, 660.

[31] W. S. Postula, Z. Feng, C. Erkey, C. V. Philip, A. Akgerman, R. G. Anthony, J. Catal. 1994, 145, 126.

[32] X. Gao, J. L. G. Fierro, I. E. Wachs, Langmuir 1999, 15, 3169.

[33] S. C. Moon, M. Fujino, H. Yamashita, M. Anpo, J. Phys. Chem. B 1997, 101, 369

[34] S. Naito, M. Tanimoto, J. Catal. 1995, 154, 306; H. J. M. Bosman, E. C. Kruissink, J. Vanderspoel, F. Vandenbrink, J. Catal. 1994, 148, 660

[35] Z. Feng, W. S. Postula, A. Akgerman, R. G. Anthony, Ind. Eng. Chem. Res. 1995, 148, 660 .

[36] a) L. Armelao, H. Bertagnolli, D. Bleiner, M. Groenewolt, S. Gross, V. Krishnan, C. Sada, U. Schubert, E. Tondello, A. Zattin, Adv Funct. Mater. 2007, 17, 1671-1681; b) L. Armelao, D. Bleiner, V. Di Noto, S. Gross, C. Sada, U. Schubert, E. Tondello, H. Vonmont, A. Zattin, Appl. Surf. Sci. 2005, 249, 277-294; c) L. Armelao, C Eisenmenger-Sittner, M. Groenewolt, S. Gross, C. Sada, U. Schubert, E. Tondello, A. Zattin, J. Mater. Chem. 2005, 15, 1838.

[37] a) L. Armelao, H. Bertagnolli, S. Gross, V. Krishnan, U. LavrencicStangar, K. Müller, B. Orel, G Srinivasan, E. Tondello, A. Zattin, J. Mater. Chem. 2005, 15, 1954; b) L. Armelao, S. Gross, K. Müller, G. Pace, E. Tondello, O. Tsetsgee, A. Zattin, Chem. Mater. 2006, 18, 6019.

[38] S. Mascotto, O Tsetsgee, K. Müller, C. Maccato, B. Smarsly, D. Brandhuber, E. Tondello, S. Gross, J. Mater. Chem. 2007, 17, 4387.

[39] F. Schüth, Handbook of Porous Solids, Vol. I, Wiley-VCH, Weinheim, 2002, p. 250

[40] J. F. Moulder, W. F. Stickle, P. E. Sobol, K. D. Bomben, Handbook of X-Ray Photoelectron Spectroscopy, (Eds.: J. Chastain, R. C. King), Perkin-Elmer Corporation, Eden Prairie (MN), 1992

[41] NIST XPS Database, X-ray Photoelectron Spectroscopy Database, Version 20.

[42] D. Briggs, M. P. Seah, Practical Surface Analysis, Wiley, New York, 1990.

[43] G. Córdoba, M. Viniegra, J. L. G. Fierro, J. Padilla, R. J. Arroyo, J. Solid State Chem. 1998, 138, 1

[44] B. Xu, L. Dong, Y. Chen, J. Chem. Soc. Faraday Trans. 1988, 94, 1905.

[45] JCPDS 48-1548.

[46] P. Scherrer, Göttinger Nachrichten 1918, 2, 98.

[47] H. P. Klug, L. E. Alexander, X-Ray Diffraction Procedures for Polycrystalline and Amorphous Materials, Wiley, New York, 1954.

[48] a) J. Peisach, W. E. Blumberg, Arch. Biochem. Biophys. 1974, 165, 691; b) B. J. Hathaway, D. E. Billing, Coord. Chem. Rev. 1970, 5 $143-207$.

[49] a) V. Bassetti, L. Burlamacchi, G. Martini, J. Am. Chem. Soc. 1979, 101, 5471; b) L. Trouillet, T. Toupance, F. Villain, C. Louis, Phys. Chem. Chem. Phys. 2000, 2, 2005-2014; c) C. Morterra, E. Giamello, G. Cerrato, G. Centi, S. Perathoner, J. Catal. 1998, 179, 111-128.

[50] V. Indovina, M. Occhiuzzi, D. Pietrogiacomi, J. Phys. Chem. B 1999, 103, 9967.

[51] K. Muraleedharan, C. K. Subramaniam, N. Venkataramani, T. K Gundu Rao, C. M. Srivstava, V. Sankaranarayan, R. Srinivasan, Solid State Commun. 1990, 76, 727.

[52] P. D. Holmes, G. S. McDougall, L. C. Wilcock, K. C. Waugh, Catal. Today 1991, 9, 15-22

[53] M. M. Natile, A. Galenda, A. Glisenti, S. Mascotto, S. Gross, unpublished results.

[54] S. Bennici, P. Carniti, A. Gervasini, Catal. Lett. 2004, 98, 187.

[55] B. K. Teo, EXAFS: Basic Principles and Data Analysis, Springer, Berlin, 1986.

[56] X-Ray Absorption: Principles, Applications, Techniques of EXAFS, SEXAFS and XANES, (Eds.: D. C. Koningsberger, R. Prins), Wiley, New York, 1988

[57] D. G. Nicholson, M. H. Nilsen, J. Mater. Chem. 2000, 10, 1965.

[58] I. J. Pickering, G. N. George, Inorg. Chem. 1995, 34, 3142. 
[59] V. Massarotti, D. Capsoni, M. Bini, A. Altomare, A. G. G. Moliterni, Z. Kristallogr. 1998, 213, 259.

[60] H. von Jaggi, H. R. Oswald, Acta Crystallogr. 1961, 14, 1041.

[61] A. Moen, D. G. Nicholson, M. Ronning, J. Chem. Soc. Faraday Trans. 1995, 91, 3189.

[62] L.-S. Kau, D. J. Spira-Solomon, J. E. Penner-Hahn, K. O. Hodgson, E. I. Solomon, J. Am. Chem. Soc. 1987, 109, 6433.

[63] J. L. DuBois, P. Mukherjee, T. D. P. Stack, B. Hedman, E. I. Solomon, K. O. Hodgson, J. Am. Chem. Soc. 2000, 122, 5775.

[64] J. E. Hahn, R. A. Scott, K. O. Hodgson, S. Doniach, S. R. Desjardins, E. I. Solomon, Chem. Phys. Lett. 1982, 88, 595.

[65] J. A. Dahl, B. L. S. Maddux, J. E. Hutchinson, Chem. Rev. 2007, 107, $2228-2269$.

[66] A. Albinati, S. Gross, M. Rancan, S. Rizzato, E. Tondello, unpublished results.
[67] G. Trimmel, S. Gross, G. Kickelbick, E. U. Schubert, Appl. Organomet. Chem. 2001, 15, 401.

[68] A. Shirley, Phys. Rev. B 1972, 5, 4709.

[69] C.-K. Wu, M. Yin, S. O'Brien, J. T. Koberstein, Chem. Mater. 2006, $18,6054$.

[70] S. Brunauer, P. H. Emmett, E. Teller, J. Am. Chem. Soc. 1938, 60, 309.

[71] M. Newville, P. Livins, Y. Yacoby, J. J. Rehr, E. A. Stern, Phys Rev. B 1993, 47, 14126.

[72] S. J. Gurman, N. Binsted, I. Ross, J. Phys. C 1986, 19, 1845.

Received: August 15, 2008

Revised: January 16, 2009 Published online: March 23, 2009 